Journal of Educational

and Psychological Sciences

Volume (5), Issue (36): 30 Sep 2021

P: 59 - 75
AJSRP

ISSN: 2522-3399
مجلة العلوم

التربوية والنفسية

المجلد (5)، العدد (36): 30 سبتمبر 2021 م

ص: 59 - 55

\title{
The challenges of employing one of the techniques of the Fourth Industrial Revolution (augmented reality) in teaching science from the point of view of female teachers the second field in Sharqiyah South Governorate
}

\author{
Basma Nasser Mohammed Al-Mashaikhi \\ Mohammed Y.M. Mai \\ Universiti Pendidikan Sultan Idris || Malaysia
}

\begin{abstract}
The present study aimed to reveal the challenges that face female teachers in the second field in applying one of the techniques of the Fourth Industrial Revolution (augmented reality). The study included teachers in the second field of schools in the South Sharqiyah Governorate, and the study relied on the descriptive survey approach in obtaining information, and the questionnaire was used as a tool to collect data using Google Forms. The study sample, which was chosen randomly, consisted of 196 teachers. The results of the study showed the existence of organizational challenges. On the other hand, the material and technical challenges came with a very high degree to apply (augmented reality) technology. In light of the results, the study recommends the need to guide the teacher using Techniques of the Fourth Industrial Revolution (Augmented Reality) by building curricula that support the employment of technology, preparing schools with devices and the Internet to keep pace with modern technologies, and developing the performance of second field teachers by attaching They are taking intensive training courses on the techniques of the Fourth Industrial Revolution (Augmented Reality)
\end{abstract}

Keywords: The Fourth Industrial Revolution, Augmented Reality, Female teachers in the second field.
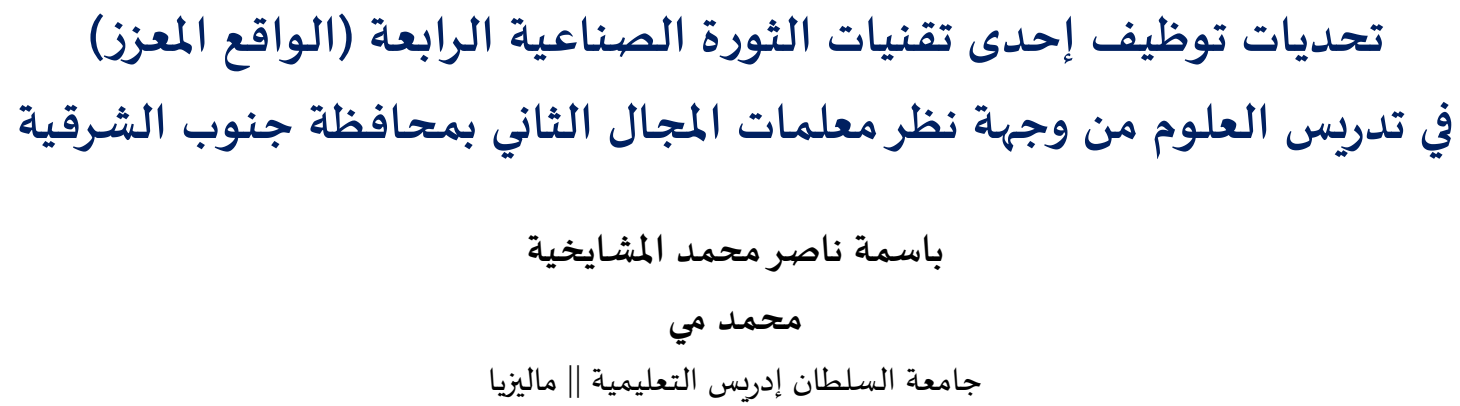

المستخلص: هدفت الدراسة الحالية إلى الكشف عن التحديات التي تواجه معلمات المجال الثاني في تطبيق احدى تقنيات الثورة

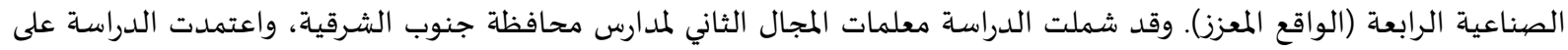

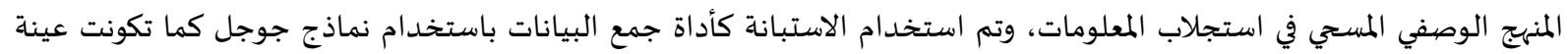

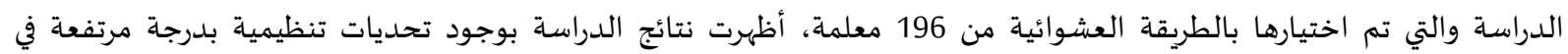

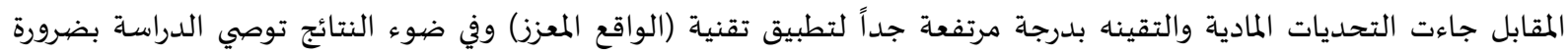
توجياه المعلم باستخدام تقنيات الثورة الصناعية الرابعة (لواقع المعزز) من خلال بناء مناهج تدعم توظيف التقانة، وتطوير أداء معلمات المجال الثاني من خلال الحاقهم بدورات تدريبية مكثفة حول تقنيات الثورة الصناعية الرابعة (الواقع المعزز). 
يواجاه العالم في العصر الحالي تغيرات سريعة وجذرية في ظل ظهور الثورة الصناعية الرابعة، التي أحدثت

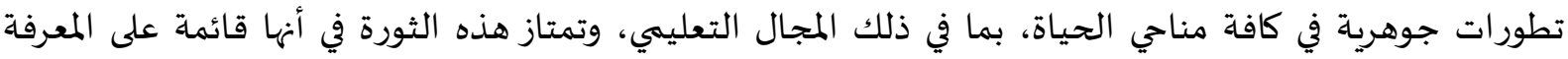
والتكنولوجيا والتي ستنعكس بشكل مباشر على التعليم والتعلم، إذ سنشهد تطورات في في الطرق والأساليب التدريس بشكل عام، وطرق تدريس العلوم بشكل خاص؛ لما لها من ظواهر علمية وتجارب عملية.

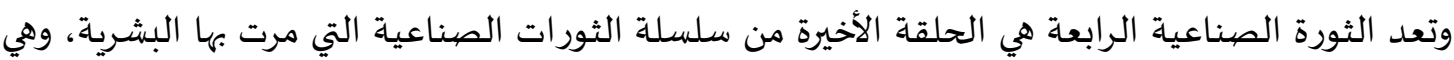

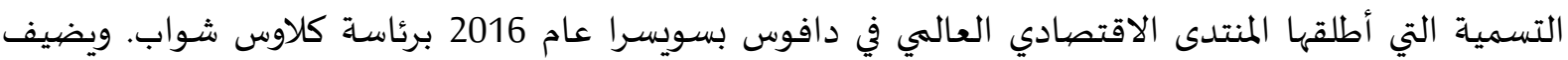
شواب (Schwab, 2016) أن الثورة الصناعية الرابعة تختلف عن الثورات السابقة؛ حيث تنتشر فيها التقنيات الناشئة على نطاق أوسع وأسرع. وأن التركيز على التعليم، وتطوير مساراته، بما يتماشى اتجاهات الثورة الرقمية الناشئة، يُعد السلاح الأقوى؛ لنهوض والتقدم بالمجتمعات المعاصرة ومواجهة تحديات هذه الثورة؛ إذ تساعد بشكل كبير في إعداد أجيال

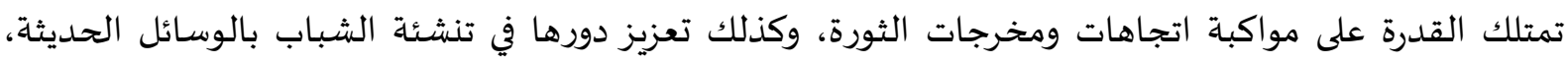

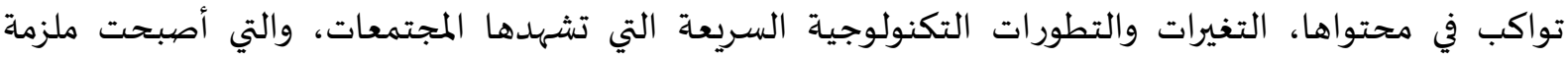
للإنسان في جوانب مختلفة (الدهشان، 2020). ومن أجل تحقيق اتحاد وإدماج مبادئ الثورة الصناعية الرابعة في مجالات التعليم فعلينا تعزيز التعان مستوى تدريس العلوم التطبيقية والتقنيات المتقدمة والحديثة والتركيز على مستوى الاحترافية والمهنية في المؤسسات التعليمية؛ لذا وجب الاهتمام بأهداف التعليم ونوعيته ليصبح هدف التعليم ليس رفع مستوى الوعي الاجتماعي والثقافي فحسب، بل توظيف وبرمجة المعرفة على أسس تنافسية ملموسة، بالإضافة إلى تقديم تجارب ناجحة

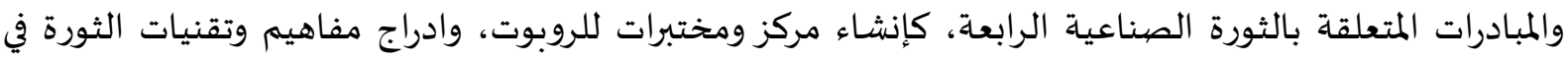

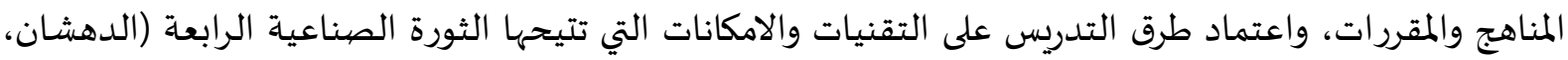

ولقد عقدت لجنة وزراء التعليم العالي والبحث العلمي بمجلس التعاون لدول الخليج العربية اجتماعها

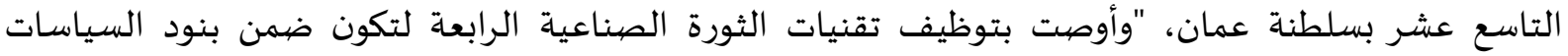
التربوية التي يمكن تطويعها لتعزيز التدريس وتمكين المعلمين، وتوفير فرص التعليم والتدريب وتنمية المهارات اللازمة للعمل والحياة في عصر الذكاء الاصطناعي". (الأمانة العامة، 2019، ص. فقرة فئرة 2). ومن بين تقنيات الثورة الصناعية الرابعة تقنية الواقع المعزز، التي بدأت فكرتها في عام 1962 باختراع

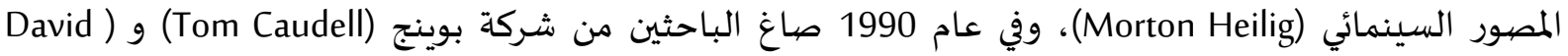
(Mizell

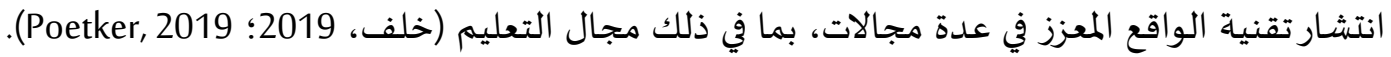

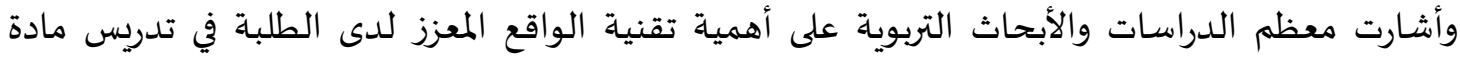

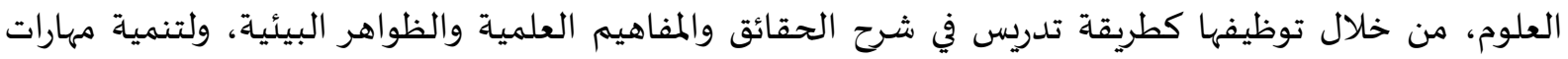
التفكير، وكما أوصت العديد من الدراسات باستخدامها لما يعزى إلهها من الأثر الإيجابي بتوظيفها في العملية

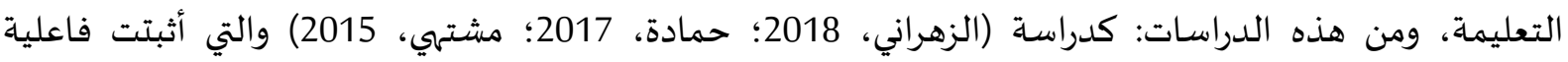


توظيف تكنولوجيا الواقع المعزز في تنمية مهارات التفكير العليا (التفكير الإبداعي)، ودراسة (محمد، 2019) التي

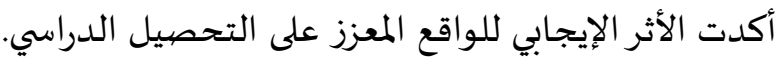
يستنتج من ذلك أن تقنية الواقع المعزز تتمتع بسمات وخصائص متعددة، وعليها إعطاء الفرصة لإسية لكل من المعلم والطالب للاستفادة منها، وذلك من خلال توظيفها في العملية التعليمة، لذا يتوجب على المؤسسات التعليمية معرفة التحديات التي تحول دون توظيفها بالصورة المطلوبة.

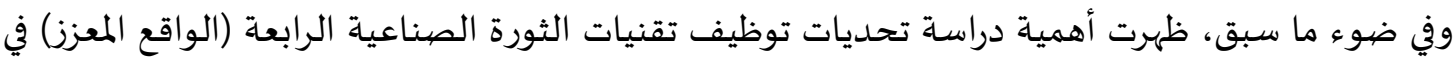
تدريس العلوم من وجهة نظر معلمات المجال الثاني بسلطنة عمان.

مشكلة الدراسة:

أحدثت الثورة الصناعية الرابعة تغيرات جذرية في الحياة البشرية، لا سيما التعليم والاقتصاد القائم على المعرفة، مما دعت الحاجة إلى أن تكون كافة المؤسسات التعليمية، أكثر جاهزية لاستخدام التكنولوجيا الحديثة في

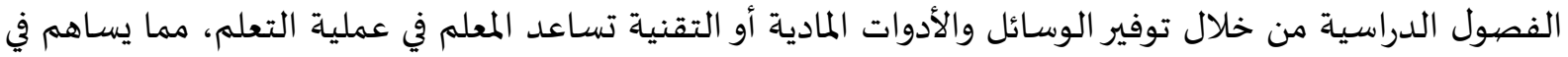
نقل التعليم من التعليم التقليدي إلى التعليم النشط القائم على طرق وأساليب واستراتيجيات الحديثة؛ لتنشئة الطلاب في المهارات الفكرية والرقمية التي تناشد بها الثورة الحالية، كونها حاجة ملحة للنهوض بالمجتمع.

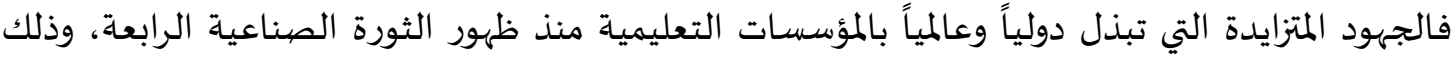
بغرض النظر إلى آلية وتقديم التعليم بطريقة جاذبة ومحفزة للإبداع والابتكاروجعل من التعليم تعليما نشطاً، والتي برزت من خلال عقد مؤتمرات عدة تدور حول أهمية الثورة الصناعية الرابعة للتعليم بشكل عام كمؤتمر الدولي في سلطنة عمان (21-23 يناير 2019) "الثورة الصناعية الرابعة وأثرها على التعليم" أخرجت التوصيات بتوظيف تقنيات ومحركات الثورة الصناعية الرابعة -كتقنية الواقع المعزز- في مناهج وطرق التدريس، وعلى المدارس أن تتحول تدريجياً من البيئة المدرسية التقليدية إلى البيئة المدرسية المتوافقة مع متطلبات الثورة المباتية الحالية (المؤتمر الدولي،

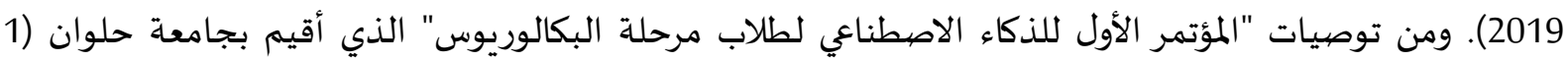
يوليو - 2020) أوصى بتحديث أساليب التدريس والارتقاء بها حتى تتماشى مع متغير التكنولوجيا الحديثة (جامعة حلوان، 2020).

ومن جانب آخر، أوصت عديد من المؤتمرات بتوظيف تقنية الواقع المعزز بشكل خاص مثل: المؤتمر الدولي

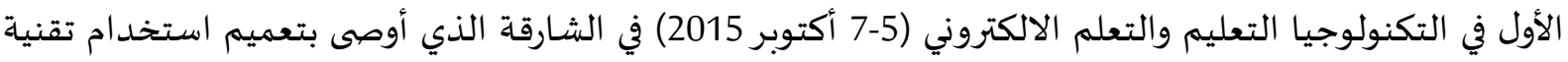
الواقع المعزز في التعليم بشكل عام وتعليم الحاسب والتكنولوجيا بشكل خاص، ومؤتمر الدولي الثالث للتعلم

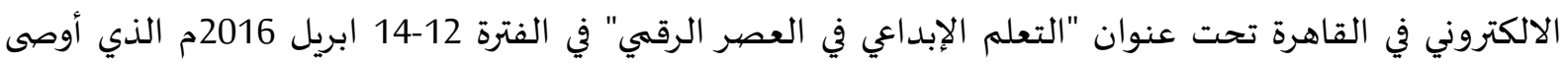
بالبحث في استخدام الواقع المعزز في التعليم. على الرغم من التوجهات التي أصبحت تناشد بتوظيف تقنيات الثورة الصناعية المعاعية الرابعة (الواقع المعزز)،

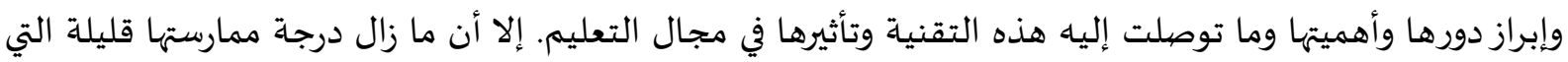
دلت على ذلك نتائج دراسة كل من الغامدي (2020) ودراسة السبيعي وعيسى (2020). علاوة على ذلك، أوصات دراسة (2018) Putiorn, Nobnop, Buathong, and Soponronnarit التي قدمت في مؤتمر القمة العالمية اللاسلكية لعام 2018 (GWS في تايلند، بضرورة الكشف والبحث عن الصعوبات التي تحد من توظيف تقنية الواقع المعزز في الفصول الدراسية. 
وتأتي هذه الدراسة بالكشف عن التحديات التي تضعف من توظيف تقنيات الثورة الصناعية الرابعة

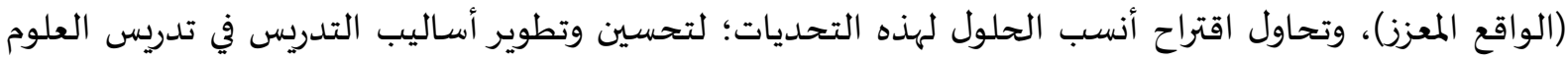
من وجهة نظر معلمات المجال الثاني.

أسئلة الدراسـة: n وبناء على ما سبق؛ تتحدد مشكلة الدراسة في السؤال الرئيسي الآتي:

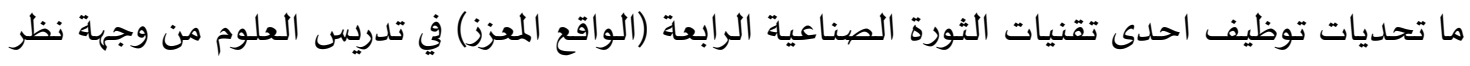

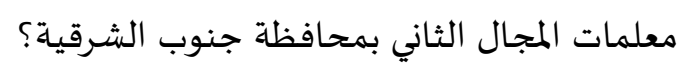
ويتفرع من السؤال الرئيسي الأسئلة الفرعية التالية: 1- ما التحديات التنظيمية التي تواجه المعلمات في توظيف تقنيات الثورة الصناعية الرابعة (الواقع المعزز)

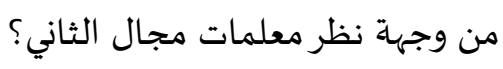
2- ما التحديات المادية والتقنية التي تواجه المعلمات في توظيف تقنيات الثورة الصناعية الرابعة (الواقع المعزز) أهداف الدراسة: سعت الدراسـة إلى تحقيق الأهداف الآتية: 1- كشف التحديات التنظيمية التي تواجه المعلمات في توظيف تقنيات الثورة الصناعية الرابعة (الواقع المعزز).

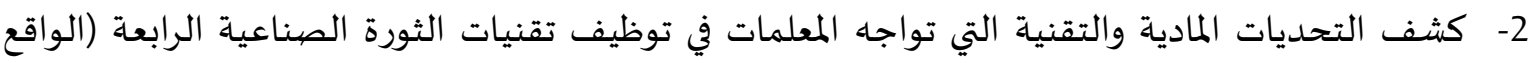

المعزز).

تتجلى أهمية الدراسة في:

الأهمية النظرية:

تأتي هذه الدراسة متزامنة مع رؤية "عُمان 2040" بتطوير المناهج ومواكبة التكنولوجيا الحديثة من خلال

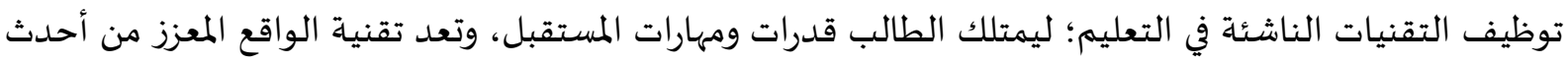
التقنيات المستخدمة في مجال التعليم مؤخرًا، وقد تشكل هذه الدراسة إضافة إلى الدراسات العربية التي تناولت

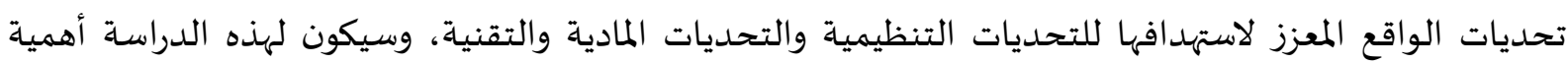

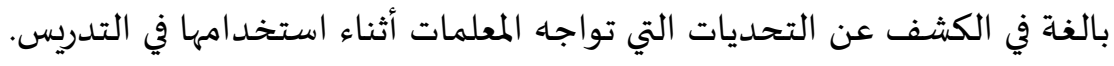

$$
\text { الأهمية التطبيقية: }
$$

قد تساهم الدراسة من خلال عرض النتائج في كشف التحديات التي تواجه المعلمة أثناء توظيفها لتقنيات الثورة الصناعية الرابعة (الواقع المعزز)، فالتركيز على التحديات يجعل من الجهات المسؤولة الماتئ وصناع القرار في معرفة الأسباب بشكل أعمق، مما توجههم للبحث عن الحلول المناسبة لتغلب عليها.

$$
\text { مبررات الدراسـة: }
$$

1- تدني في درجة ممارسة المعلمين لتقنيات الثورة الصناعية الرابعة (الواقع المعزز) وتوظيفها في العملية التعليمة

$$
\text { بحسب ما جاءت باه نتائج الدراسات السابقة. }
$$


2- عدم وجود دراسة عمانية تناولت تحديات تقنيات الثورة الصناعية الرابعة بشكل عام، وتقنيه الواقع المعزز بشكل خاص- على حد علم الباحثين-. 3- جاءت هذه الدراسة استجابة لتوصيات المؤتمرات والدراسات السابقة.

حدود الدراسة:

اقتصرت الدراسة الحالية على الحدود الآتية:

الحد الموضوعي: تقنيات الثورة الصناعية الرابعة: تم اختيار تقنية الواقع المعزز؛ لأنه يمكن تطبيقها في الغرف التهاه الصفية بسهولة، وتتوفر التطبيقات مجانية، وكما أهها مناسبة للمرحلة الدراسية المستهدفة. الحد البشري: تكون مجتمع الدراسة من جميع معلمات المجال الثاني البالغ عددهن (400)، وتم تطبيق الدراسة على عينة عشوائية تبلغ (196) معلمة.

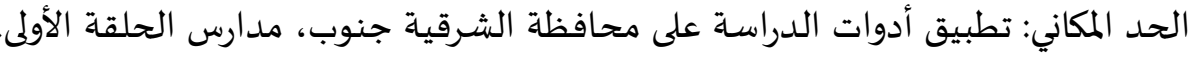
الحد الزماني: تطبيق في الفصل الأول من العام الدراسي 2020 / 2021 م. مولـ

مصطلحات الدراسة: - التحديات: وتعرف بأنها: "مجموعة من الازمات أو المشكلات أو التغيرات المعاصرة التي تواجه نظم التعليم"

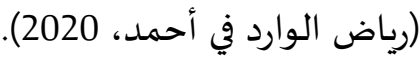
O متعرف إجرائيا: هي المشكلات والصعوبات التي تواجه معلمة المجال الثاني بتوظيف تقنيات الثورة الصناعية الرابعة (الواقع المعزز) وتحد من تحقيق الأهداف التعليمية للمادة العلوم. وتقاس من خلال استجابة أفراد العينة لأداة الدراسة (الاستبانة). - الثورة الصناعية الرابعة (The Fourth Industrial Revolution): وتُعرف بأهها: "هي الثورة الرقمية الثانية، يقودها عدد من التقنيات، وتتميز بدمج هذه التقنيات التي تُزيل الخطوط الفاصلة بين المجالات المادية والرقمية والبيولوجية" (Schwab, 2016, P.12). O وتعرف إجرائيا بأنها: مجموعة من التقنيات وتتضمن تقنية الواقع المعزز توظفها معلمة المجال الثاني في الحصية

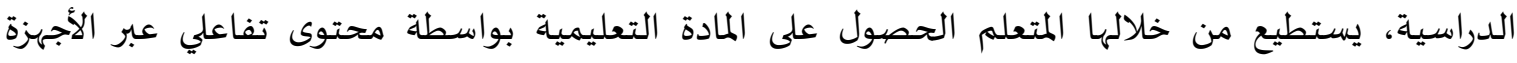
المحمولة المتصلة بالشبكة العنكبوتية. - الواقع المعزز: تعرف على أنها: "دمج للواقع الافتراضي مع الواقع الحقيقي بواسطة أجهزة الحاسوب يمكن

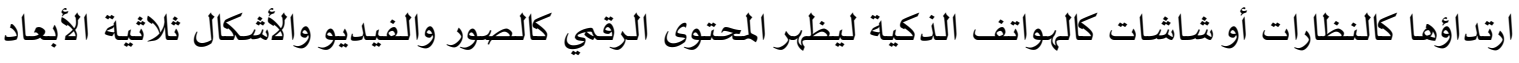

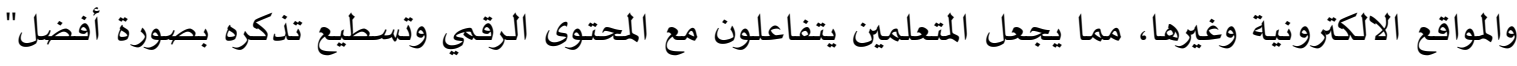

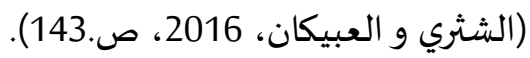

O مويعرف اجرائيا بأنها مجموعة من التطبيقات في الأجهزة اللوحية والهواتف الذكية توظفها معلمات المجال الثاني لدمج العالم الحقيقي مع العالم الافتراضي، من خلال ربط بلائ محتوى الكتاب بالصهور ومقاطع فيديو وأشكال ثنائية وثلاثية الابعاد بواسطة الحاسوب، يشاهدها الطلبة بتوجيه كاميرا الهاتف الذكي المتصل بالأنترنيت الى صفحات الكتاب، من أجل تفاعل الطالب مع المادة العلمية وربطها بحياته الواقعية. - معلمات المجال الثاني: معلمات اللاتي يدرسن مادتي الرياضيات والعلوم لطلاب الحلقة الأولى. 
لقد مرت الصناعة بعدة مراحل التي وردتها الأدبيات والدراسات، النشأة التاريخية لمراحل الثورة الصناعية

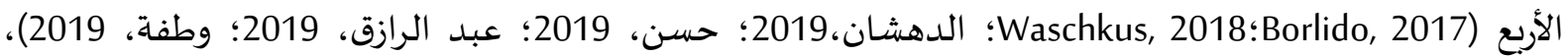

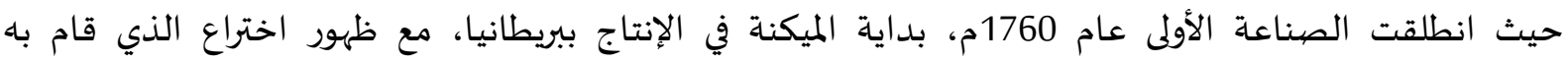

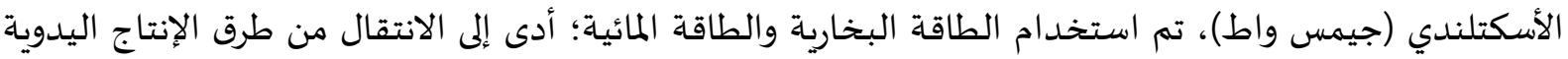

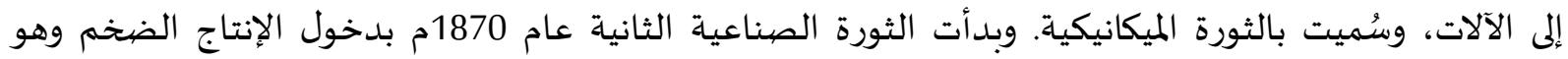

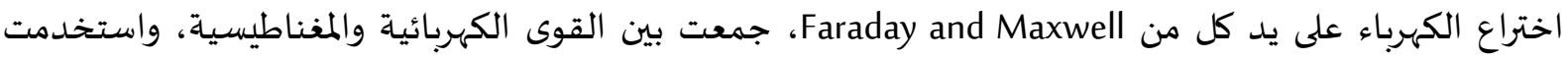

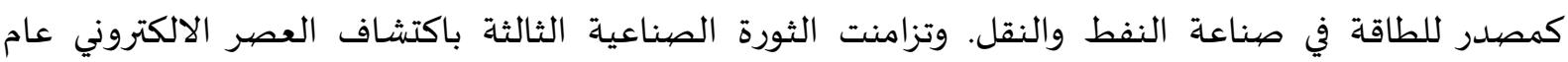
1969م، وسُميت بالثورة الرقمية؛ ويُنظر إليها على أهها ثورة معلوماتية؛ سهلت الوصهول إلى المعلومات وانتشارها

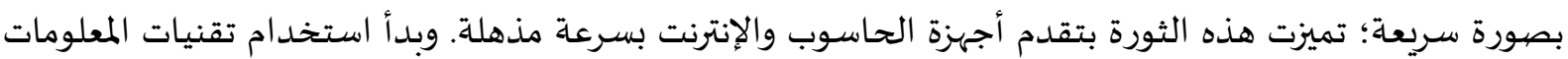
في جميع مجالات حياتنا.

ويشهد العالم اليوم ثورة كبيرة وهي الثورة الصناعية الرابعة التي تم استخدامها لأول مرة في عام 2011 في

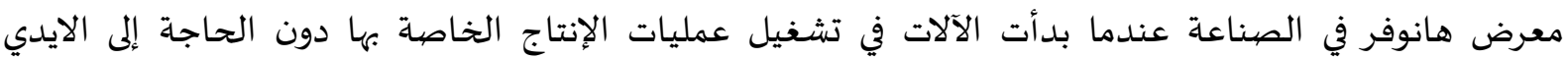

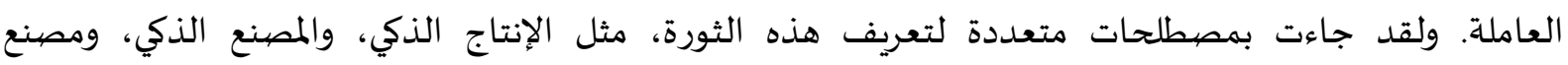
المستقبل، والثورة الصناعية الرابعة، والصناعة 4.0 (Laudante, 2017). ويتضح بأن الصناعة مرت بالعديد من التغييرات عبر التاريخ نمت بالتتابع مع الاكتشافات والتطورات التهات التي التهاتي

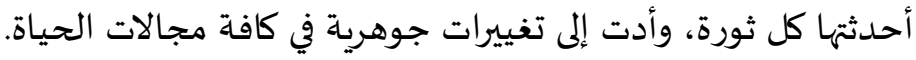

\section{مفهوم الثورة الصناعية الرابعة: - م}

لقد عرف Schwab (2016 الثورة الصناعية الرابعة بأنها ثورة الأنظمة الفيزيائية السيبرانية، أي عصر

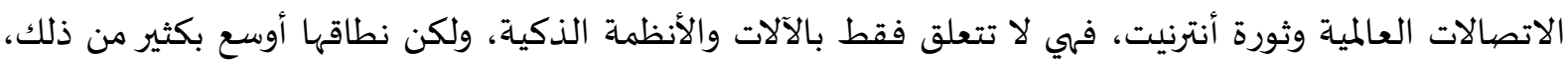
تحدث في وقت واحد موجات من اختراقات في عدة مجالات بما في ذلك الروبوتات، والذكاء الاصطناعي، وتكنولوجيا

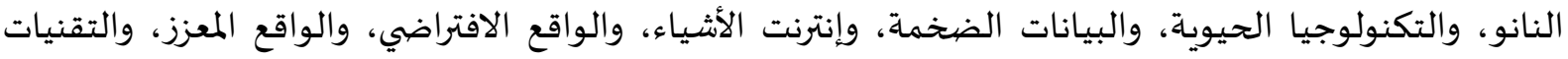

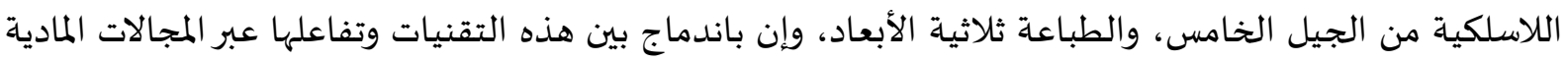

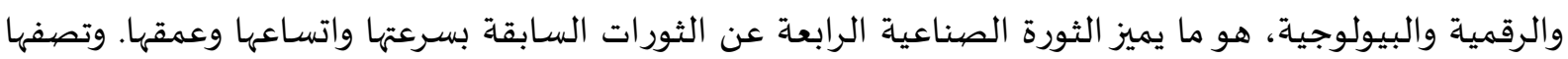

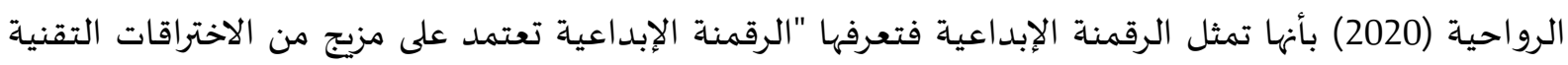

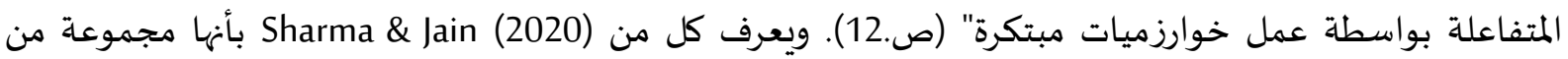
التقنيات ومنظمات سلسة القيمة داخل المصانع الذكية التي تعتمد على انترنيت الأشياء في عملها، وتراقب الأنظمة الفيزيائية السيبرانية العملية الفيزيائية، وإنشاء نسخة افتراضية من الفيات العالمالم المادي، تساعد في اتخاذ قرارات

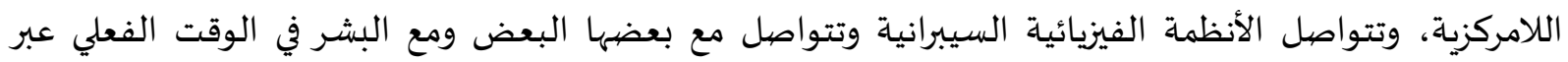

ويمكن تلخيص مفهوم الثورة الصناعية الرابعة بأنها رقمنه إبداعياه تقودها عدد من المحركات كالذكاء الاصطناعي، وأنترنيت الأشياء، والبيانات الضخمة، وتكنولوجيا النانو، الروبوتات، والواقع الافتراضي، والواقع المعزز، إنهاء 
وإن بدمج هذه التقنيات تزيل الخطوط الفاصلة بين المجالات المادية والرقمية والبيولوجية، يجلب العالم الحقيقي إلى واقع افتراضي، وتسمح بتواصل الآلات مع بعضها لبعض وتهاء بلفاعل الانسان مع التكنولوجيا في الوقت الفعلي بواسطة الأنترنيت؛ لإنشاء بيئات ذكية.

تقنيات الثورة الصناعية الرابعة: تتميز الثورة الصناعية الرابعة بمحركات تقودها كأنترنيت الأشياء، والأنظمة السبيرانياة، والذكاء الاصطناعاعي، والروبوتات، والواقع المعزز، وغيرها؛ لتحسين الكفاءة وزيادة في الإنتاج (الرواحياة، 2020). وإن من أهم التقنيات التي تقود الثورة الصناعية الرابعة كما يوضحها الشكل (1).

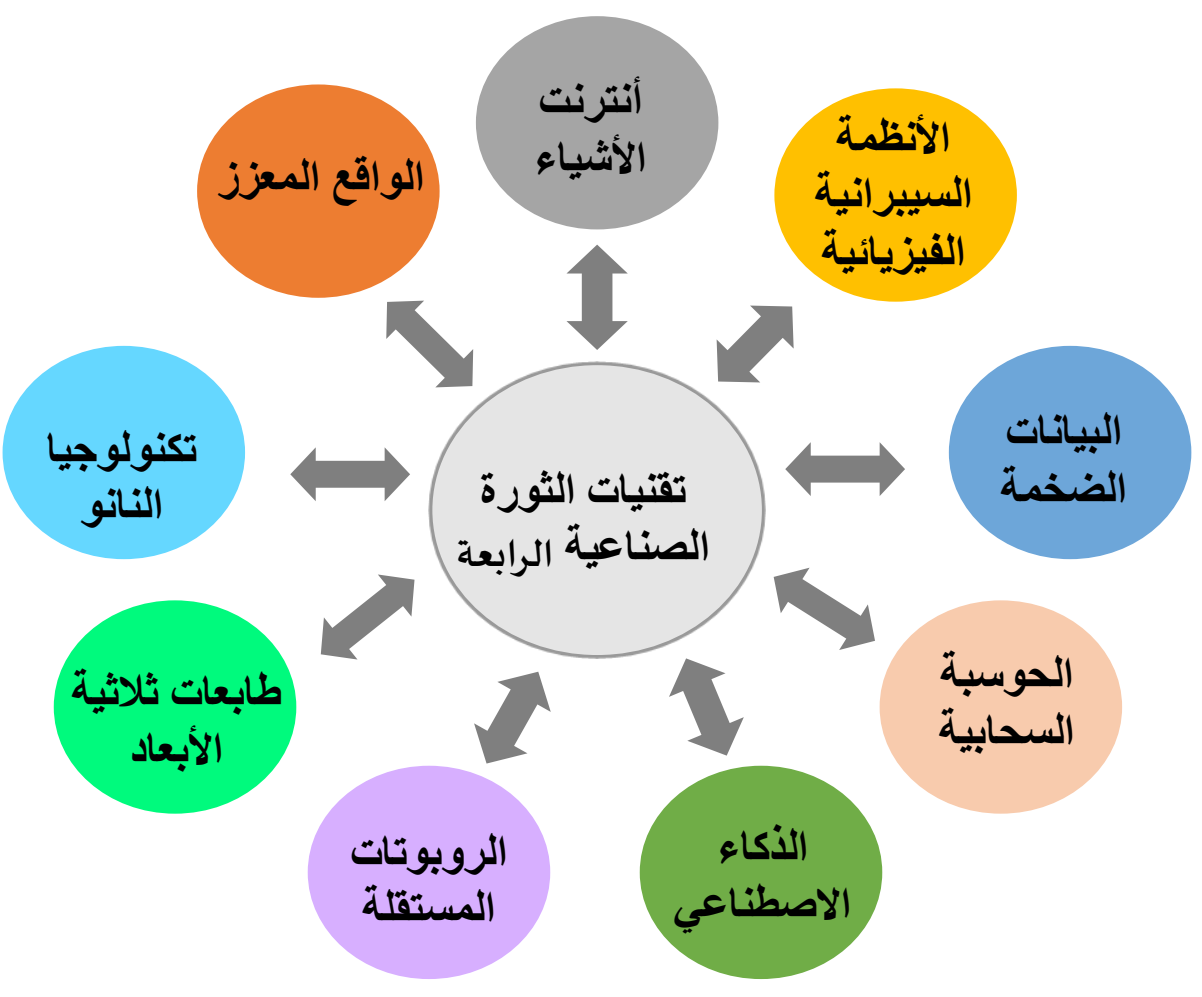

$$
\begin{aligned}
& \text { الشكل (1) تقنيات الثورة الصناعية الرابعة }
\end{aligned}
$$

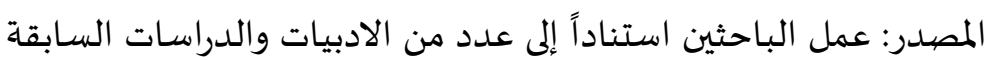

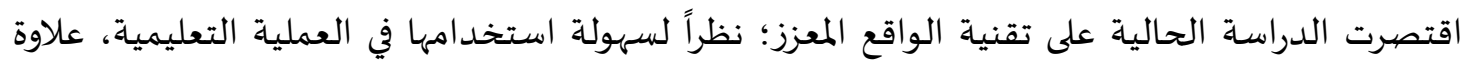

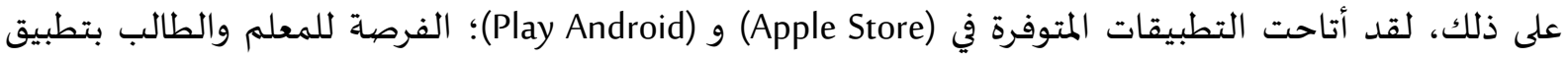
التجارب التي يصعب تنفيذها على أرض الواقع بكل سهولة؛ حتى يتمكن المعلم من توظيفها في كل مرحلة من مراحل

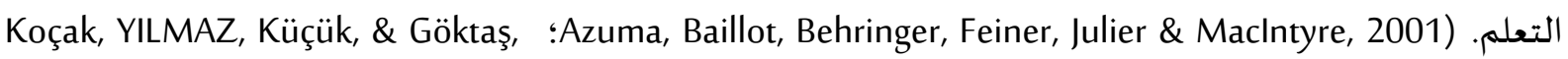

شهد العالم مؤخرًا العديد من التغييرات على المستوى التقني في ظل الثورة الصناعية الرابعة، وفي ظل الماتل ظهور الأجهزة الذكية تزامن ظهور تقنيات متعددة، والتي احتوت على مجموعة من التطبيقات التي قد تحتاج إلى 
برمجة بسيطة ويسهل استخدامها، وتقنية الواقع المعزز هي إحدى هذه التقنيات الناشئة من هذه الثورة. وتم استخدامها في عدة مجالات من بينها مجال التعليم (الريامياة، 2019).

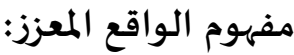

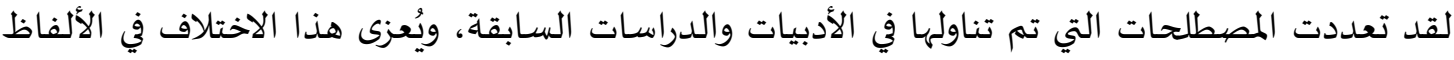

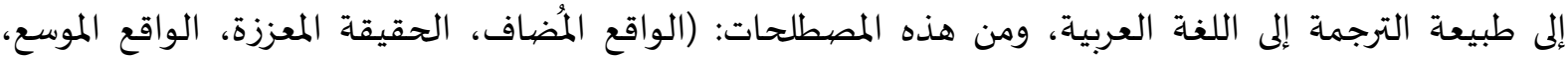
الواقع المدمج، الواقع المحسن)، ويُعد مصطلح الواقع المعزز أكثرشهرة بعديه المهند الترجمة.

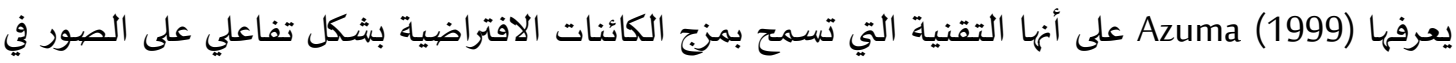

الوقت الفعلي.

في حين عرفها (2014) Dunleavy تقنية حديثة تستخدم فيها الأجهزة الذكية التي تدرك السياق كالهواتف

الذكية والأجهزة اللوحية، التي تمكن المستخدمين من التفاعل مع المعلومات الرقمية المضمنة في البيئة المادية.

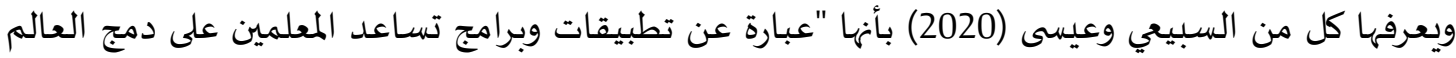

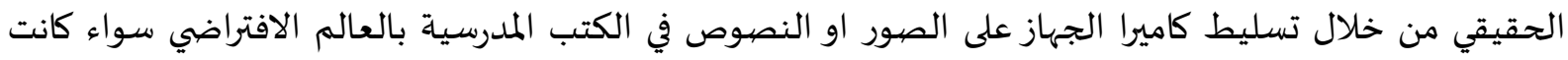

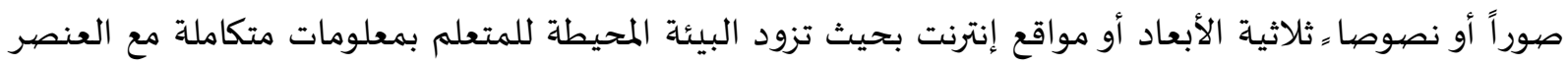

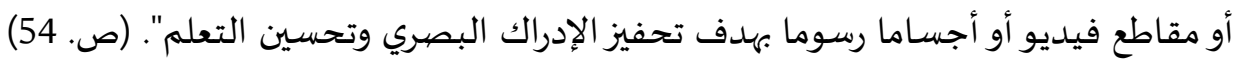

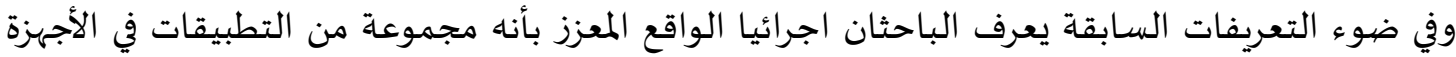

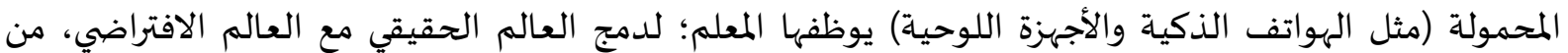
خلال ربط محتوى الكتاب بالصور ومقاطع فيديو وأشكال ثنائية وثلاثية الابعاد بواسطة الحاسوب، يشاهدها

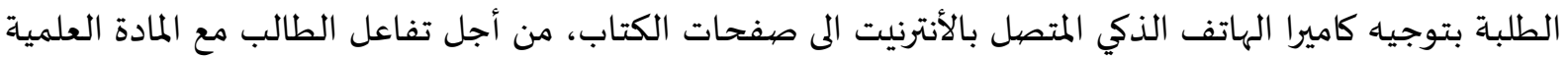
وربطها بحياته الواقعية.

أهمية الواقع المعزز في التعليم: تلعب تقنية الواقع المعزز دورا بارزا في عملية التعلم؛ حيث إنها تساعد الطلبة على التعلم بشكل مستقل،

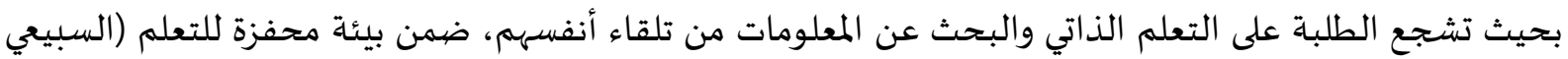
وعيسى، 2020). وإن من خلال الميزة التي توفرها تقنية الواقع المعزز، في إمكانية رؤية الكائنات الافتراضية المضافة في

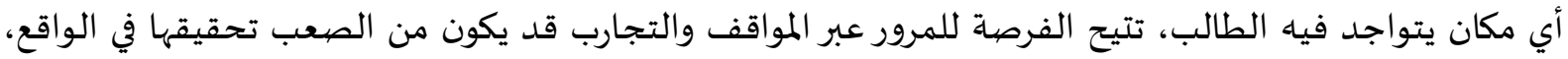

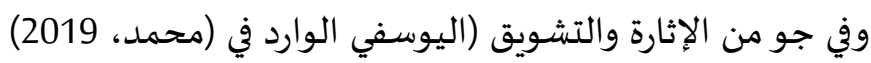
لذا من الضروري توظيف تقنية الواقع المعزز في تدريس العلوم بشكل خاص، لأنها تشجع على التفكير

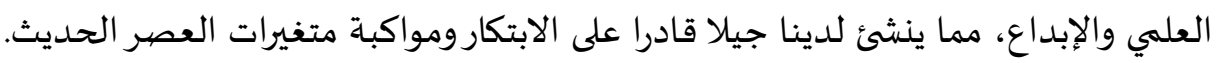

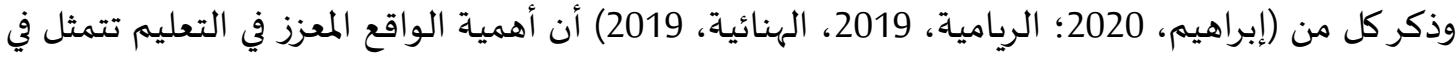

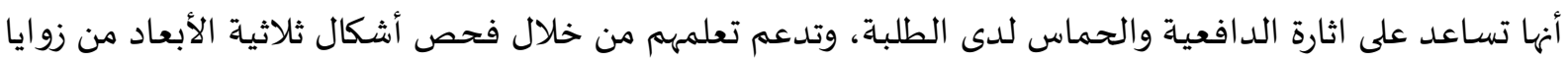

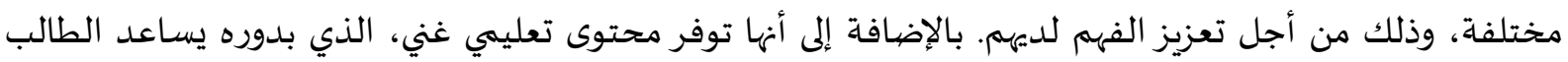

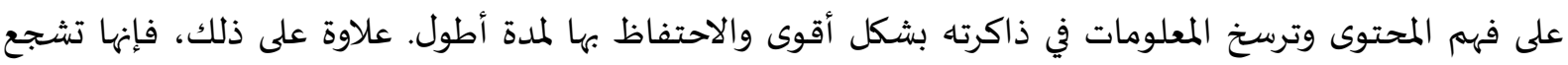

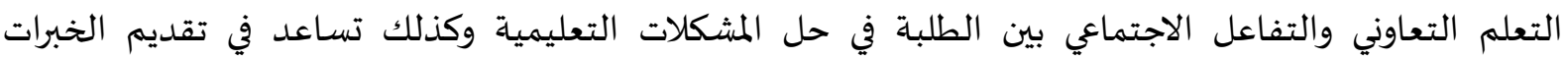

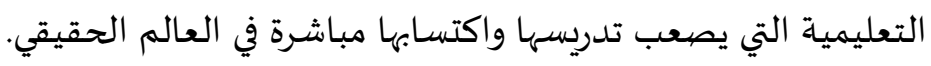


وفي هذا الصيدد أضافت دراسة الغامدي (2021) أهمية أخرى للواقع المعزز، بأنها تجعل المعلومة أو الشيء المراد توضيحه من خلالها وكأنه واقعي يتجسد أمام أعين الطلبة، مما يساعدهم على الماسها الابداع والابتكار.

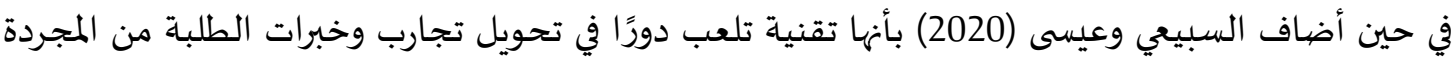

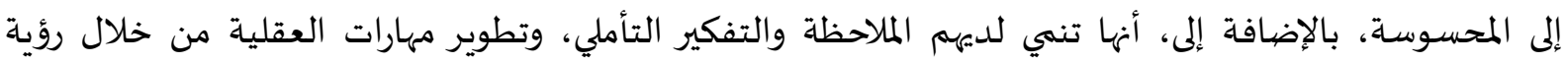

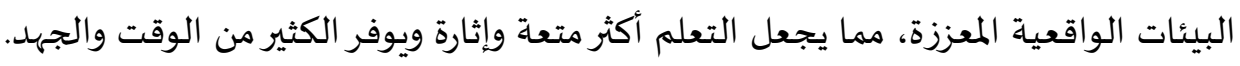

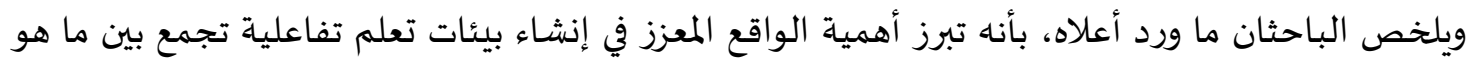

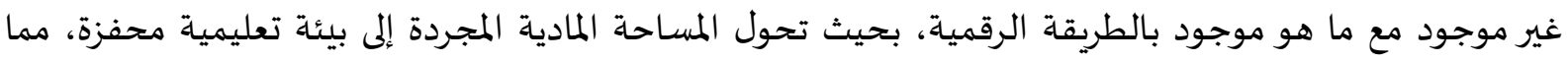

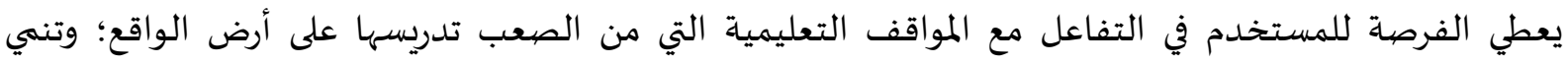
مهارات التفكير العليا لدى الطلبة ويحسن دافعيتهم للتعلم.

ثانياً- الدراسات السابقة: تتناول الدراسة عدداً من الدراسات التي ترتبط بموضوع الدراسة ومشكلتها.

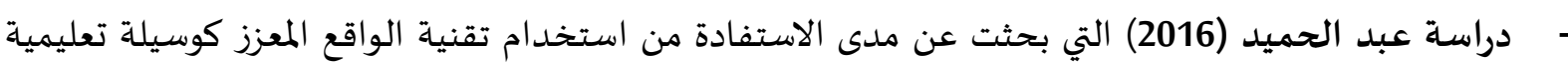

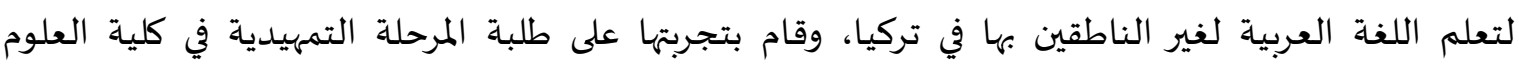

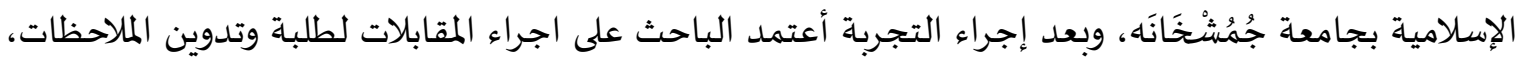

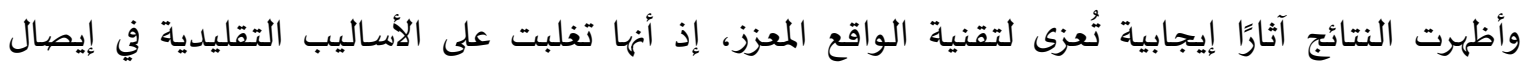

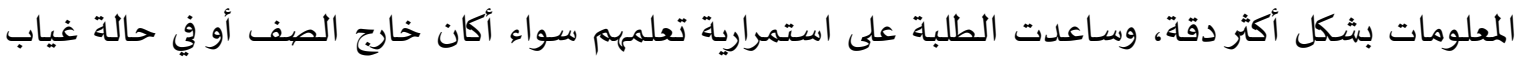

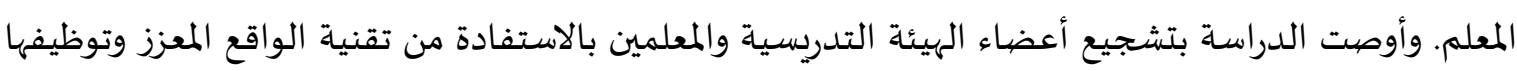

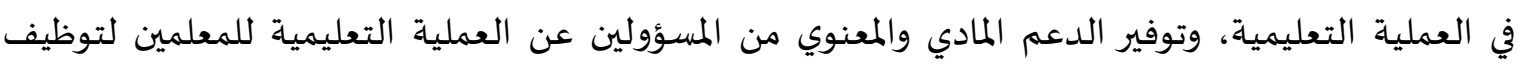
تقنية الواقع المعزز بالشكل المطلوبة التعليمية وتوفير الدعب وهدفت دراسة بوتيورن (Putiorn \& other 2018) إلى كشف عن تصورات المعلمين والمعلمات تجاه استخدام

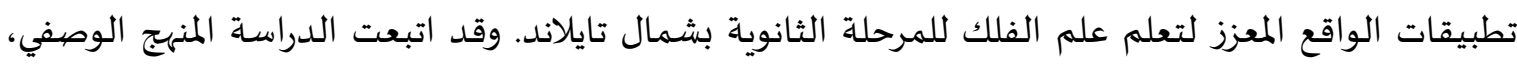

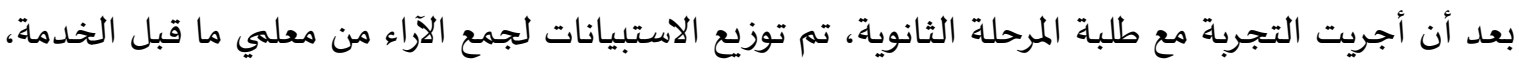

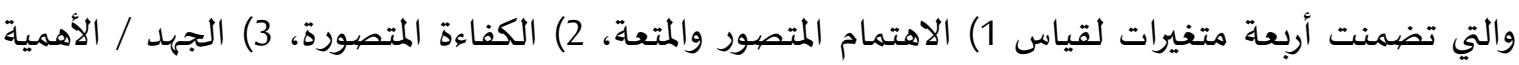

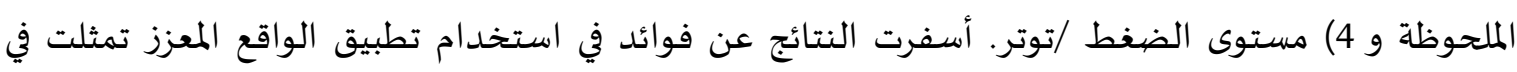

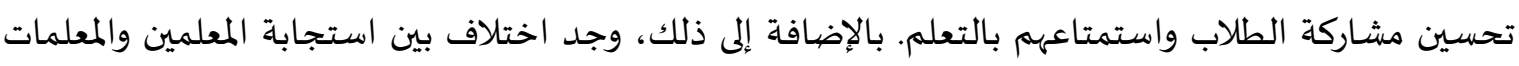

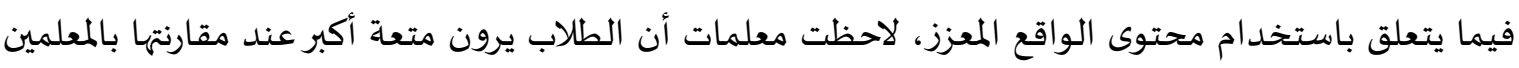

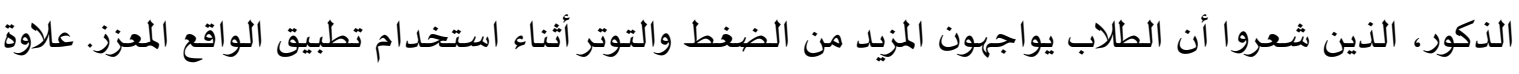

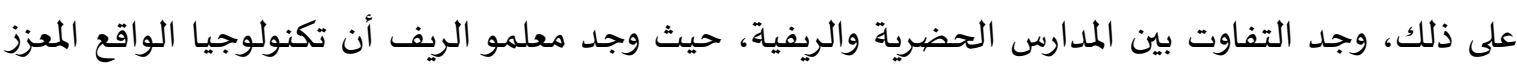

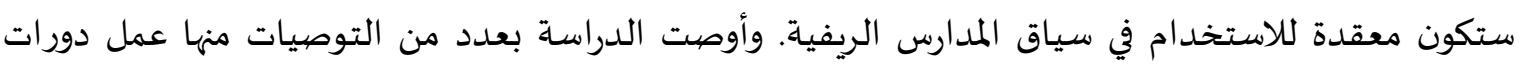

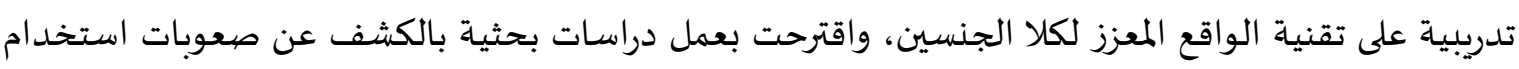
الواقع المعزز في الفصول الدراسية. وأجرت الحويطي والبلوى (2019) دراسة هدفت إلى الكشف عن اتجاهات معلمات الرياضيات للمرحلة

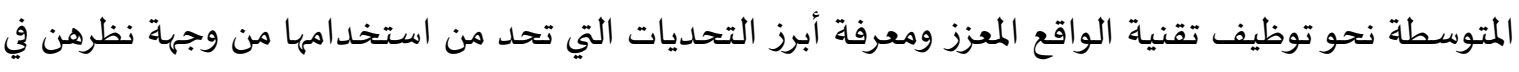

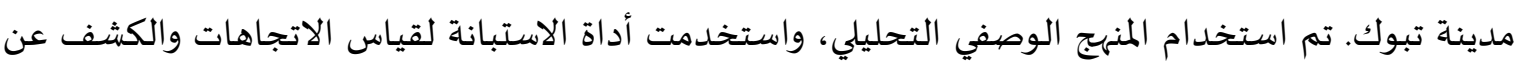


التحديات، وتكونت العينة من (55) معلمة رياضيات. وقد أسفرت النتائج عن اتجاهات إيجابية وبدرجة عالية

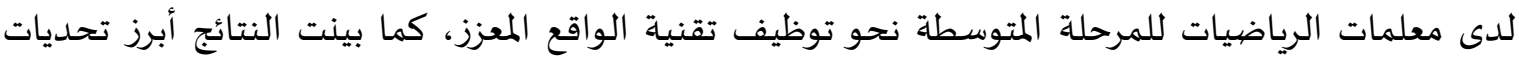
التي تحول دون استخدام تقنية الواقع المعزز تمثلت في: عدم امتلاك الطالبات للأجهزة، ضعف في شبكات الاتصال، قلة وجود المختصين لمساعدة المعلمة لإيجاد المحتوى المناسب لتقنية الواقع المعزز، وقت الحصية غير كافي لاستخدام تقنية الواقع المعزز، صعوبة في استخدام تقنية الواقع المعزز في المناطق النائية. واستقصت دراسة أوسونا وزملاءه (Osuna, Gutiérrez-Castillo, Llorente-Cejudo, \& Ortiz, 2019) في الكشف عن الصعوبات دمج الواقع المعزز في التعليم الجامعي في إسبانيا، وذلك بالبحث عن التحديات التقنية والمنهجية التي قد يواجهها أعضاء هيئة التدريس عند تطبيق تقنية الواقع المعزز في التعليم الجامعي. نم استخدام المنهج الوصفي المستي على عينة تكونت من (115) من أعضاء هيئة التدريس، وتم استخدم أداة الاستبانة. وكشفت النتائج عن ضعف تدريب أعضاء الهيئة التدريسية، ونقص في الدعم المؤسسي بتوفير الموارد والأجهزة لتوظيف التقنية. - وأجرت البوسعيدية (2019) دراسة هدفت إلى معرفة اتجاهات معلمات مدارس ما بعد الأساسي بمحافظة

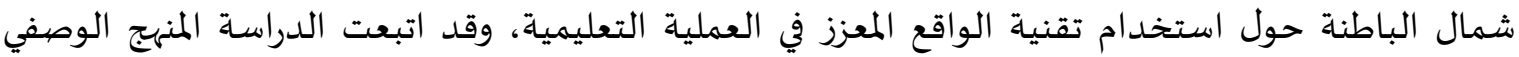
باستخدام آداه الاستبانة، تكونت العينة من (45) معلمة اللاتي استخدمن التقنية في مدارسهن على مستوى المحافظة، وأسفرت النتائج إلى اتجاهات إيجابية مرتفعة جداً لدى المعلمات لاستخدام تقنية الواقع المعزز،

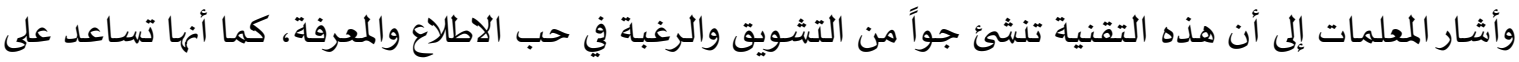

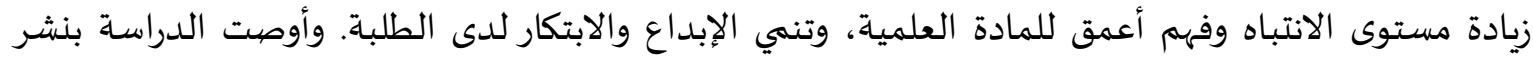
الوعي بأهمية توظيف تقنية الواقع المعزز في التدري، وإقامة ورش تدريبية للمعلمين والمعلمات لكافة المراحل التعليمية حول كيفية استخدام التقنية. وسعت دراسة مجيد والزهراني (2020) إلى كشف التحديات التي تحول دون تطبيق تقنية الواقع المعزز في تنمية مهارات الاجتماعية للطالبات ذوات الإعاقة الفكرية في المرحلة الابتدائية من وجهة نظر المعلمات، استخدمت المنهج الوصفي، وتكونت آداه البحث من استبانة. وتكونت عينة الدراسة من (85) معلمة من معلمات التربية الفكرية بمنطقة جدة للتعرف على أبرز اختلافات الموجودة فيما بينهن في تقدير التحديات التي تحد من استخدام تقنية الواقع المعزز وفقا لعدد من المتغيرات ومنها: سنوات الخبرة، عدد الدورات التدريبية في مجال

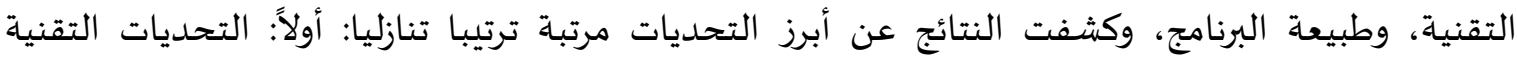

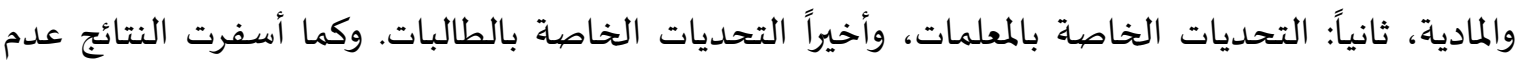
وجود فروق ذات دلالة إحصائية بين استجابات المعلمات تعزى لمتغير سنوات الخبرة، وعدد دورات المبات التدرببية، وكذلك طبيعة البرنامج. وهدفت دراسة الطويرقي (2020) التي اتبعت المنهج الوصفي، إلى الكشف عن أبرز التحديات التي تواجه

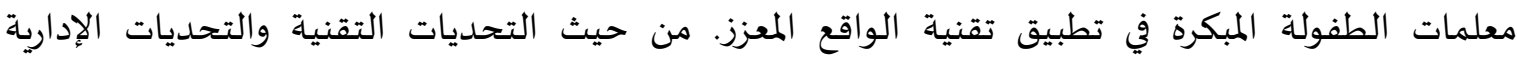

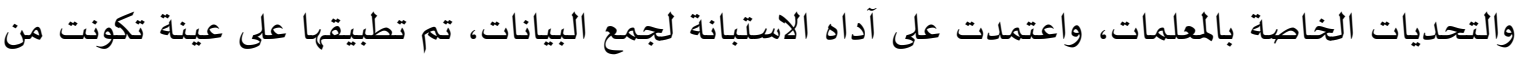

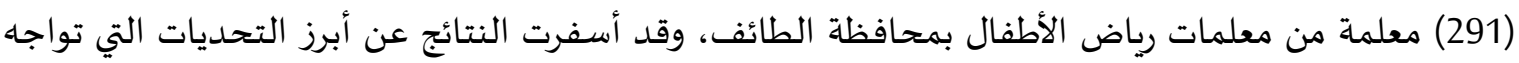

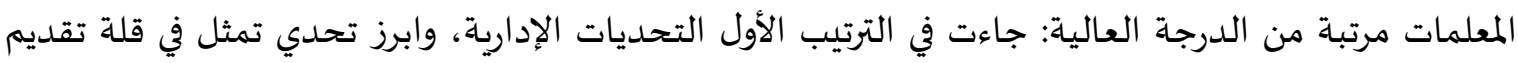

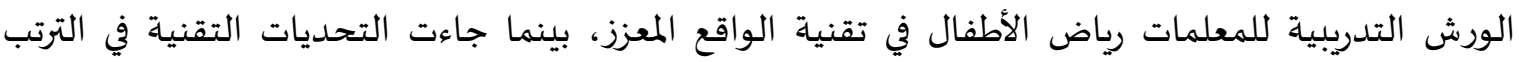

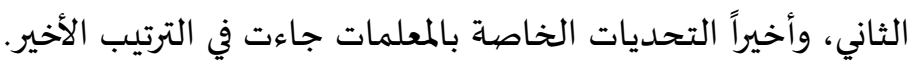


تعليق على الدراسـات السـابقة:

من خلال عرض الدراسات السابقة التي أجريت في مجال الدراسة الحالية، فقد ركزت على تصورات

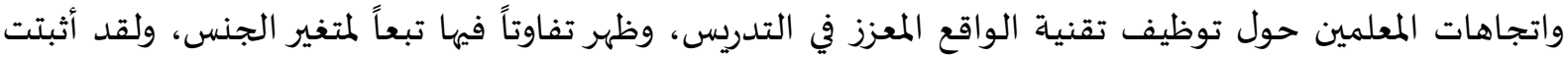
النتائج الاتجاه الإيجابي في توظيف هذه التقنية لتحسن تعلم الطلبة، وتتفق الدراسـة الحالية مع الدراسات السابقة بأهمية توظيف تقنية الواقع المعزز في العملية التعليمة، ورفح كفاية المعلمين لتطبيقها عملياً بشكل فعال، ولكنها تتفق بشكل رئيسي مع دراسة مجيد والزهراني (2020) ودراسة الطويرقي (2019) ودراسة (2019) Osuna \& other التي بحثت في تحديات تقنية الواقع المعزز في التدريس وفي استخدام المنهج الوصفي، والتي تناولت مرحلة الطفولة المبكرة وطلبة الجامعة وطلبة الدمج، في حين تختلف الدراسة الحالية في التقصي خلف تحديات التي تواجها المعلمات

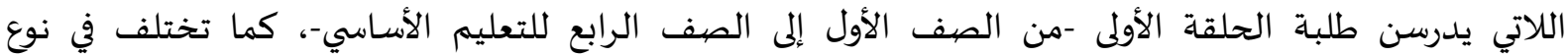
التحديات حيث أهها تناولت التحديات التنظيمية والتحديات المادية والتقنية في أثناء توظيف التقنية لتدريس العلوم. وقد استفادت الدراسة الحالية من الدراسات والأبحاث السابقة: في الاطلاع على الأدبيات وبحوث والدراسات التي تناولت تقنية الواقع المعزز بشكل عام وتحدياتها على وجه الخصوص، وساعدت على إعداد وتجهيز الإطار النظري وبناء أداة البحث (الاستبانة).

3. منهجية الدراسة وإجراءاتها.

\section{المنهجية}

استخدم الباحثان المنهج الوصفي الذي يهدف إلى "جمع بيانات دقيقة لظاهرة معينة بطريقة كمية أو نوعية، من أجل التعرف على الظاهرة من حيث المحتوى والمضمون والوصول إلى نتائج وتعميمات تساعد في فهم الواقع الحالي والتطوير منه". فالهدف الأساسي من المنهج الوصفي هو "فهم الحاضر لتوجيه المستقبل" (عليان، 2001، ص.47).

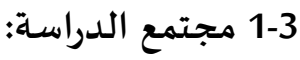
يتكون مجتمع الدراسة من جميع معلمات المجال الثاني بمحافظة جنوب الشرقية -أحد محافظات سلطنة

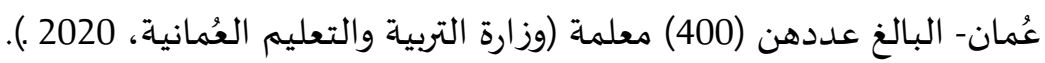

2-3 عينة البحث:

تم اختيار عينة الدراسة بالطريقة العشوائية البسيطة. ووفقا لجدول Krejcie and Morgan (الأكاديميون العرب، 2018)، فقد تكونت عينة الدراسة من (196) معلمة من معلمات المجال الثاني.

3-3 أداة الدراسة:

نظرا لان الدراسة الحالية تهدف التعرف إلى تحديات توظيف تقنية الواقع المعزز في تدريس العلوم من وجهة نظر المعلمات بمحافظة جنوب الشرقية، تم تصميم استبانة لجمع البيانات، بالاستفادة من الدراسات ذات الصلة، وبعد إجراء بعض التعديلات. وقد تكونت الاستبانة من (12) عبارة، موزعة في محورين:

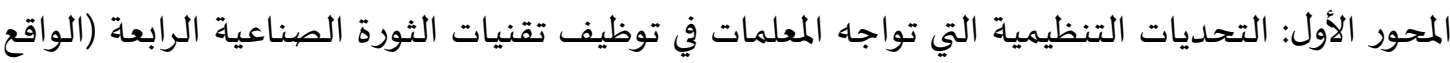
المعزز). بواقع 6 فقرات. 
المحور الثاني: التحديات المادية والتقنية التي تواجه المعلمات في توظيف تقنيات الثورة الصناعية الرابعة

$$
\text { (الواقع المعزز). } 5 \text { فقرات }
$$

الصددق والثبات:

تم التحقق من صدق الاستبانة وذلك بعرضها على مجموعة من المحكمين المختصين بلغ عددهم (6)

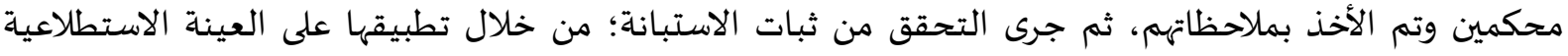
تكونت من (50) معلمة، لاستخراج معامل ثبات ألفا كرونباخ الذي بلغ (0.836) ودلّ على صلاحية هلية الأداة لاستخراج ما صهمم لأجله.

وتم استخدام أسلوب الإحصاء الوصفي لتحليل البيانات، لاستخراج الأوساط الحسابية والانحرافات المعيارية، والمستوى والرتبة لجميع عبارات محاور الاستبانة، ولكل محور من المحاور.

\section{4-3 الأساليب الإحصائية المستخدمة في البحث:}

تم بإدخال البيانات الكترونيا، وتمت معالجة الإحصائية باستخدام الأساليب الإحصائية الآتية:

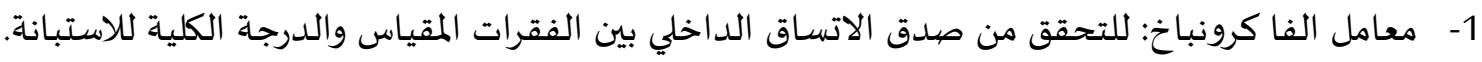

$$
\text { 2- المتوسطات الحسابية والانحرافات المعيارية. }
$$

\section{4. عرض نتائج الدراسـة ومناقشتها.}

النتائج المتعلقة بالإجابة عن السؤال الأول: ما التحديات التنظيمية التي تواجه المعلمات في توظيف تقنيات

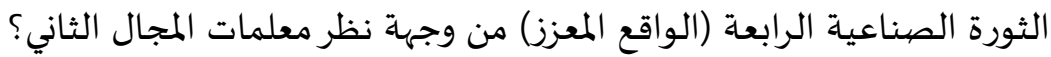

وللإجابة على هذا السؤال: لقد تم حساب المتوسطات الحسابية والانحرافات المعيارية لاستجابات عينة

الدراسة على فقرات ومحاور الاستبانة. يعرض الجدول (1) عبارات المحور الأول التحديات التنظيمية التي تحول دون استخدام تقنية الواقع المعزز في تدريس العلوم من وجهة نظر معلمات المجال الثاني.

\begin{tabular}{|c|c|c|c|c|c|}
\hline 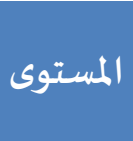 & 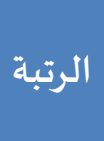 & 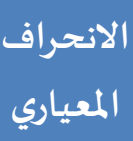 & المتوسط & 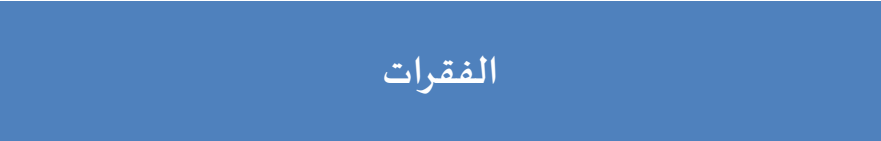 & $\hat{r}$ \\
\hline 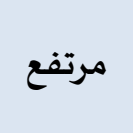 & 1 & 0.77 & 4.10 & تشكل المهام المتعددة عائقًا امام المعلمة في توظيف تقنية الواقع & 1 \\
\hline 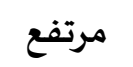 & 2 & 0.77 & 4.04 & قلة توفير فرص حقيقية لتدريب المعلمات على استخدام التقانة. & 2 \\
\hline 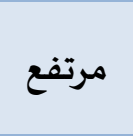 & 3 & 0.72 & 4.01 & يمثل عدد الطلبة في الفصل تحدياً عند استخدام تقنية الواقع & 3 \\
\hline 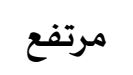 & 4 & 1.00 & 3.68 & تقيد معلمات المجال الثاني بأساليب ووسائل تعليمية محدددة. & 6 \\
\hline 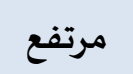 & 5 & 0.76 & 3.60 & إلزام المعلم بإنهاء المنهج الدراسي في وقت محدد. & 4 \\
\hline متوسط & 6 & 1.10 & 2.93 & قلة دعم إدارة المدرسة لاستخدام تقنية الواقع المعزز. & 5 \\
\hline
\end{tabular}

الجدول (1) استجابات عينة الدراسة على فقرات المحور الأول (التحديات التنظيمية) 


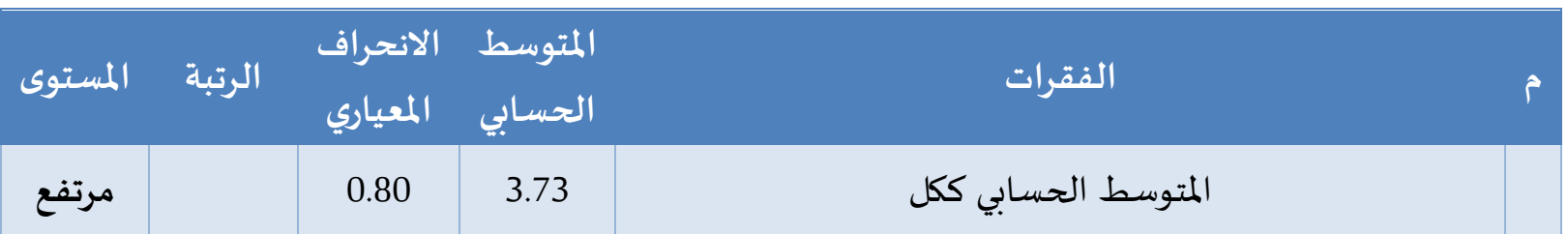

يتضح من الجدول (1) أهم التحديات التنظيمية التي تواجه معلمات المجال الثاني بتوظيف تقنية الواقع المعزز في تدريس العلوم من وجهاة نظرهن، إذ بلغ المتوسط الحسابي للمحور ككل (3.73)، ويدل ذلك على التى اتفاق

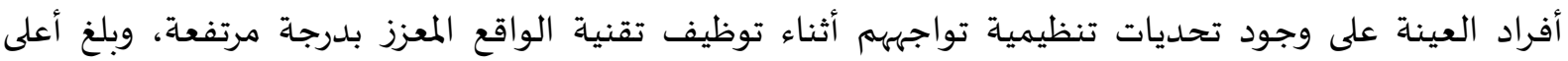

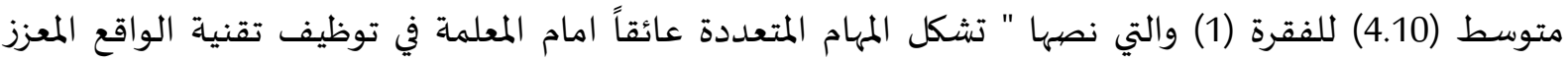

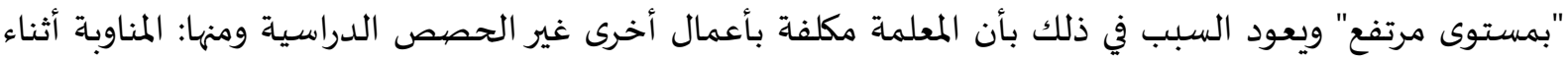

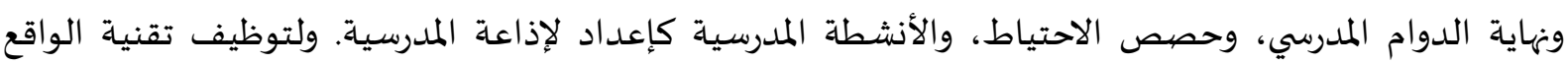

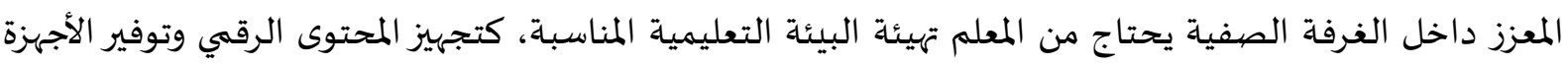

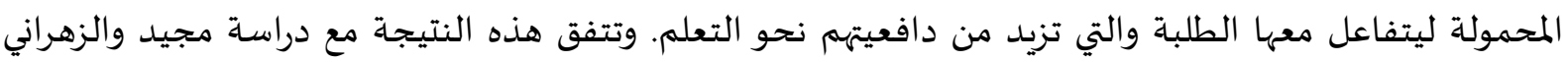

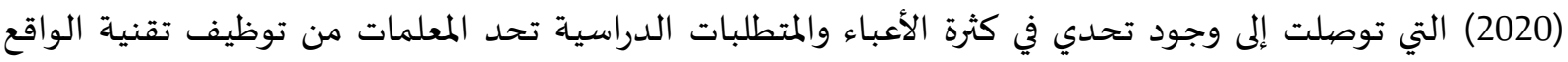
المعزز في داخل الغرفة الصفية. أما فقرة "قلة توفير فرص حقيقية لتدريب المعلمات على استخدام التقانة" جاءت في الترتيب الثاني بمتوسط حسابي (4.04) بدرجة مرتفعة، ويعزى ذلك إلى أن المعلمات هن بحاجة إلى التدريب على مهارة استخدام

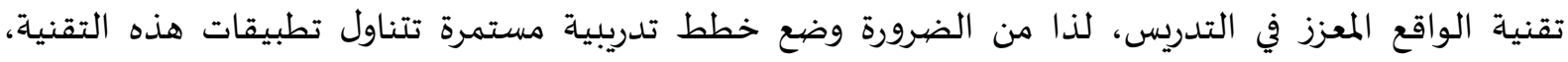

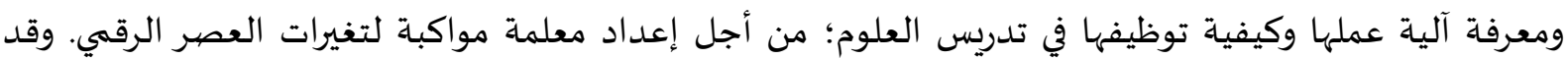

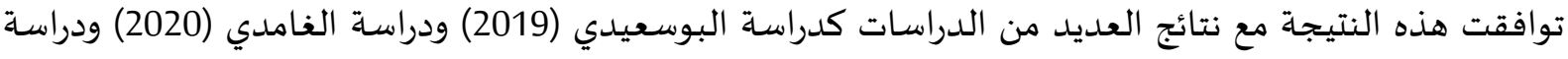
الطويرقي (2019) وأوصت بضرورة عقد دورات تدريبية عن تطبيقات الواقع المعزز في كيفية توظيفها في التدريس. في حين جاءت فقرة " قلة دعم إدارة المدرسة لاستخدام تقنية الواقع المعزز" بالمرتبة الأخيرة بدرجة الماتية

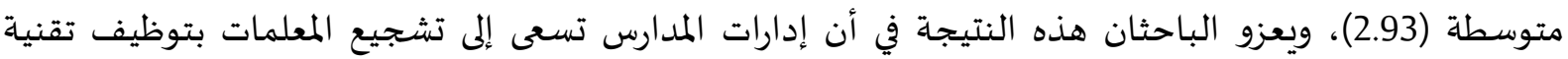

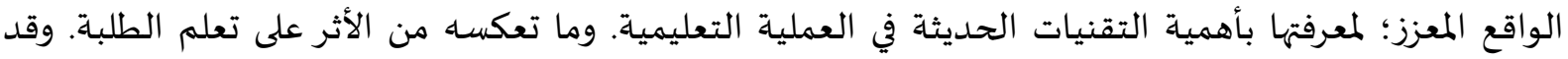

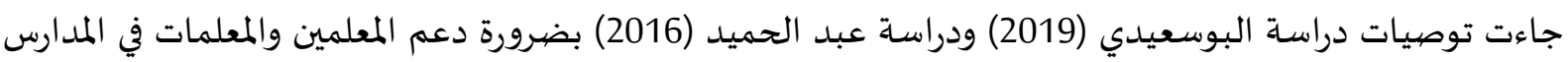
لتوظيف تطبيقات تقنية الواقع المعزز والاستفادة منها في العملية التعليمية.

النتائج المتعلقة بالإجابة عن السؤال الثاني: ما التحديات المادية والتقنية التي تواجه المعلمات في توظيف

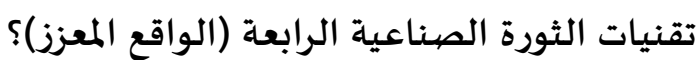

وللإجابة على هذا السؤال ومعرفة مستوى التحديات المادية والتقنية التي تواجه معلمات المجال المال الثاني في توظيف تقنية الواقع المعزز في تدريس العلوم، تم حساب المتوسطات الحسابية والانحرافات المعيارية لجميع فقرات

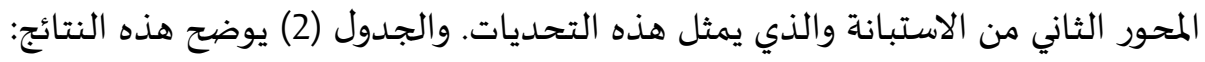

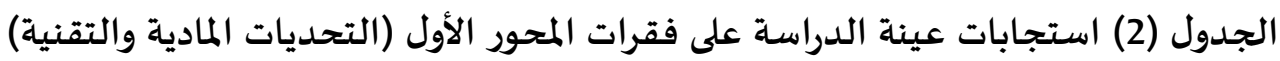

\begin{tabular}{|c|c|c|c|c|c|}
\hline الميستوى & الرتبة & المعياري & المتوسط المسبي & الفقرات & $\hat{\imath}$ \\
\hline 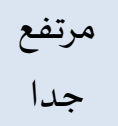 & 1 & 0.80 & 4.34 & ضعف في توفر شبكة الأنترنيت التي تدعم تقنية الواقع المعزز اثناء & 8 \\
\hline
\end{tabular}


المجلة العربية للعلوم ونشر الأبحاث ـ مجلة العلوم التربوية والنفسية ـ المجلد الخامس ـ العدد السادس والثلاثون ـ سبتمبر 2021م

\begin{tabular}{|c|c|c|c|c|c|}
\hline المستوى & الرتبة & المعياري - الانحراف & المتوسط المسابي & الفقرات & p \\
\hline & 2 & 0.84 & 4.31 & عدم وجود مصادر الكترونية وفق المنهاج تصلح لاستخدام تقنيات & 10 \\
\hline & 3 & 0.93 & 4.27 & تصميمات المناهج الحالية لا تمكن المعلم من استخدام تقنيات & 9 \\
\hline مرتفع & 5 & 0.93 & 4.12 & التكلفة المادية المرتفعة لشراء الأجهزة (الهواتف الذكية، تابلت) & 7 \\
\hline مرتفع & 6 & 0.84 & 3.95 & عدم تقديم الدعم الفني للمعلمات أثناء تطبيق تقنية الواقع & 11 \\
\hline مرتفع & & 0.86 & 4.20 & المتوسط الحسابي ككل & \\
\hline
\end{tabular}

يتبين من الجدول (2) أن المتوسط العام لاستجابات أفراد عينة الدراسة لهذا المحور جاءت مرتفعة جداً

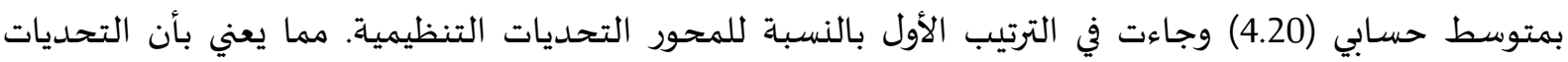

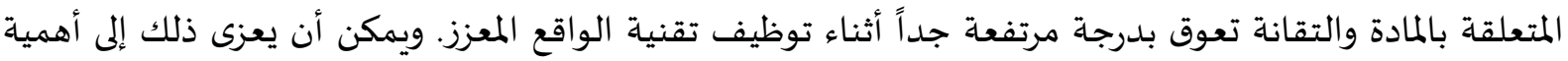

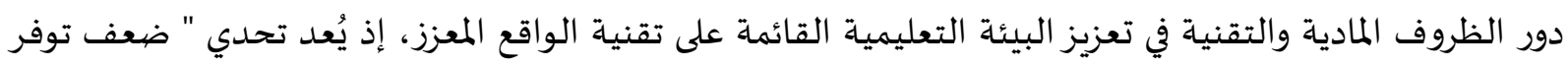

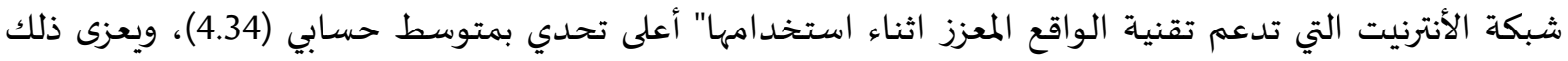
بأن يتطلب توظيف تقنية الواقع المعزز في الفصول الدراسية إلى شبكة اتصال بالأنترنيت بحيث تكون متصلية

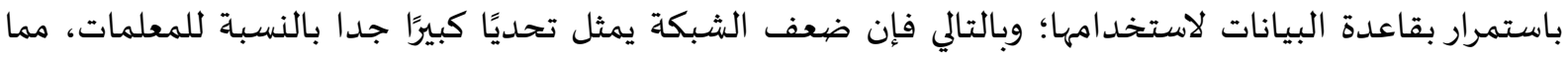
يدفع بعض المعلمات بتوفير شبكة الانترنيت على حسابها الخاص من أجل توظيفها في التدريس.

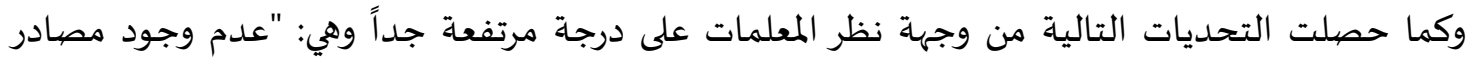

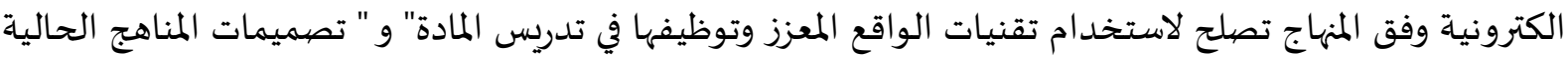

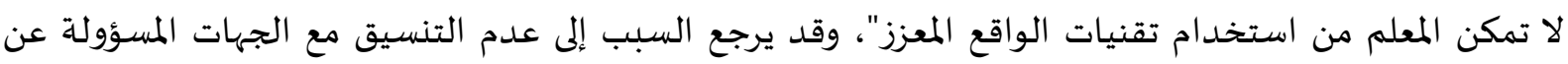

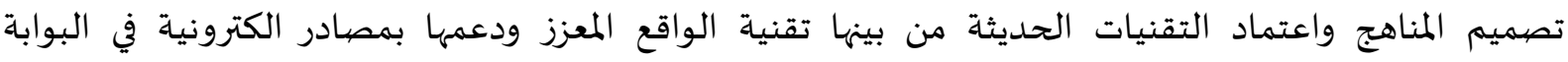
التعليمياة، التي بدورها توجه المعلم بشكل مباشر في توظيف التقنية.

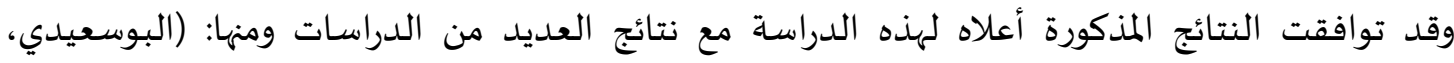
2019؛ الطويرقي، 2019؛ الغامدي، 2020؛ كنساوي، 2020؛ مجيد والزهراني، 2020).

توصيات الدراسة ومقترحاتها.

في ضوء ما توصلت إليه الدراسـة من نتائج، يوصي الباحثان ويقترحان ما يلي:

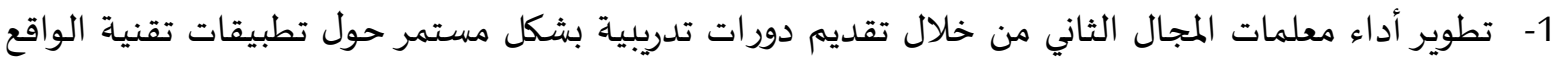
المعزز.

2- المساهمة في توفير البنية التحتية التي تدعم توظيف التقانة في العملية التعليمية. 3- تطوير المناهج توجه المعلم نحو استخدام تقنية الواقع المعزز في تدريس العلوم. 
4- إنشاء محتوى رقمي في البوابة التعليمية الخاصة بسلطنة عمان؛ تُمكن المعلم من استخدام تقنية الواقع المعزز في تدريس المواد، ومادة العلوم بشكل خاص.

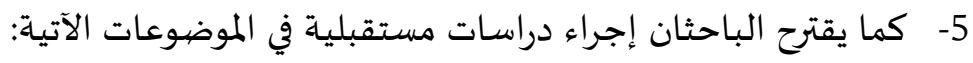

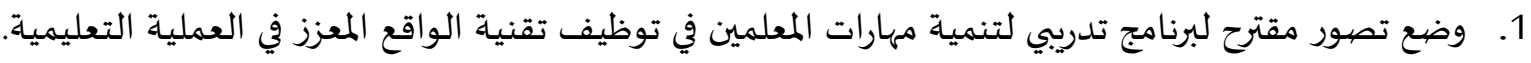

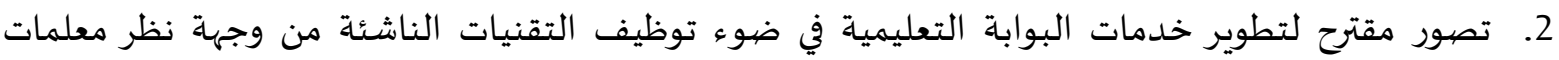
المجال الثاني.

- إبراهيم، هاشم عمر. (2020). تقنية الواقع المعزز وفائدتها في التعليم. تم الاسترداد من تعليم جديد: https://www.new-educ.com/\%D8\%AA\%D9\%82\%D9\%86\%D9\%8A\%D8\%A9-A7 - أحمد، إسماعيل عثمان حسن. (2020). تحديات التعليم الرقهي في الوطن العربي رؤية تأصيلية. المجلة العبية للتربية النوعية 4 (12)، 91- 108.

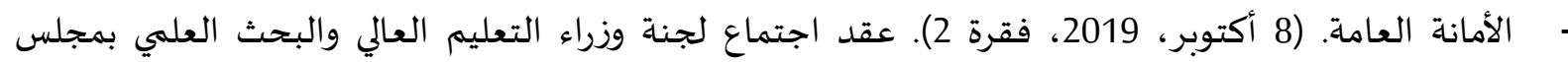

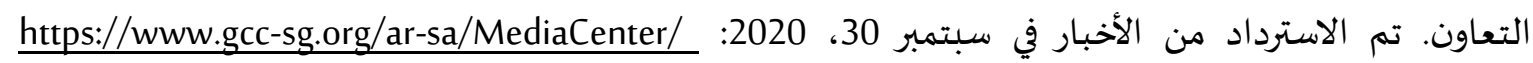
/News/Pages/news2019-10-8-1.aspxNewsCooperation - البوسعيدية، أسماء بنت سيف؛. (2019، يناير 21- 23). اتجاهات معلمات مدارس ما بعد الأساسي في محافظة

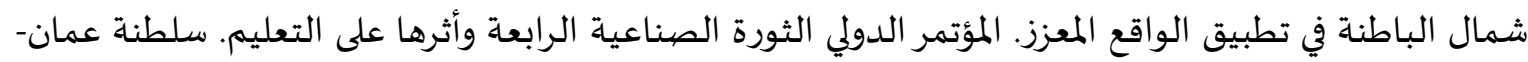
صحار: المديرية العامة للتربية والتعليم بمحافظة شمال البال الباطنة. جامعة حلوان. (2020،August 13 ). توصيات المؤتمر الأول للذكاء الاصطناعى لطلاب مرحلة البكالوريوس. تمانه

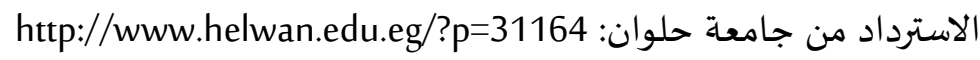

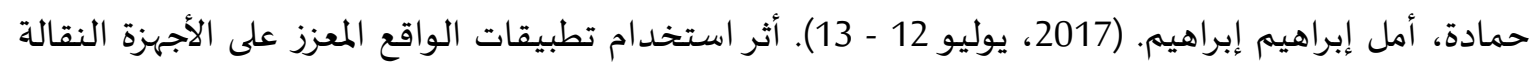

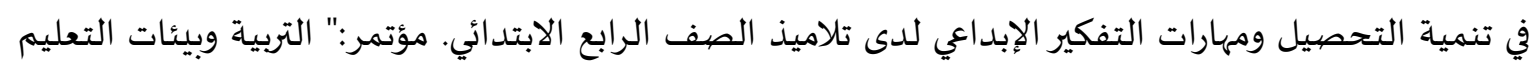

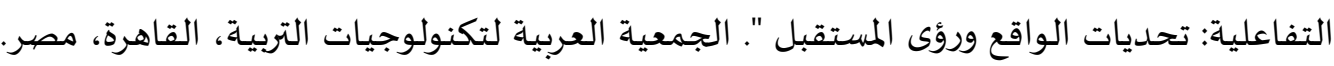

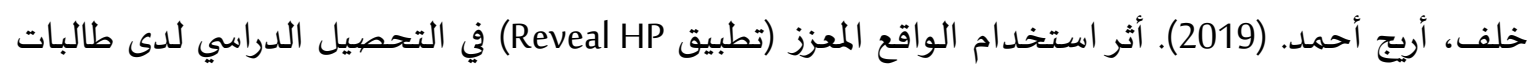

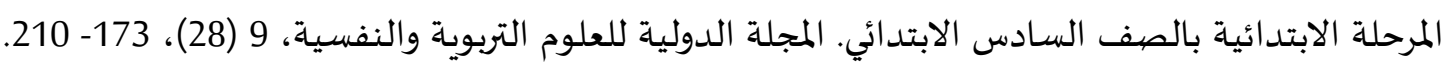

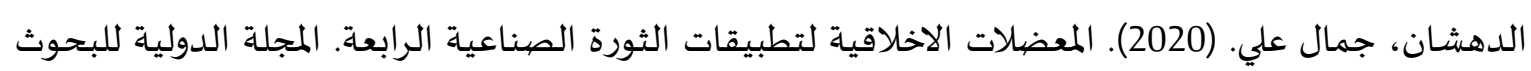

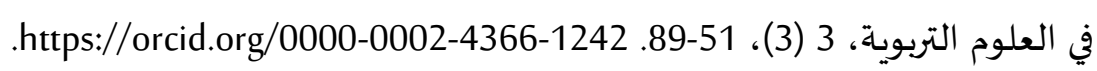
ـ ـ ـ الرواحية، زهرة بنت راشـد. (2020). صناعة المستقبل بتقنيات الثورة الصناعية الرابعة. مطبعة عمان للنشر.

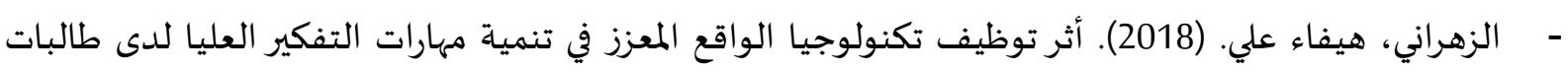

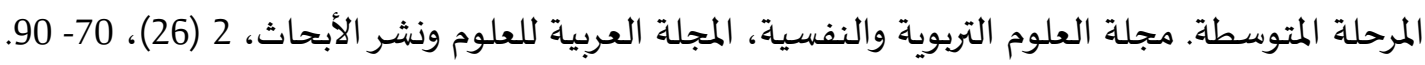

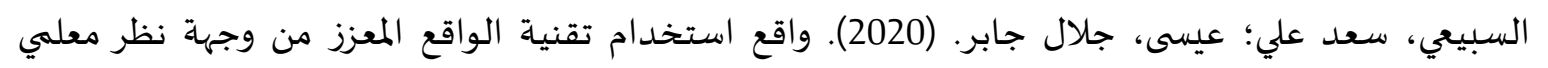

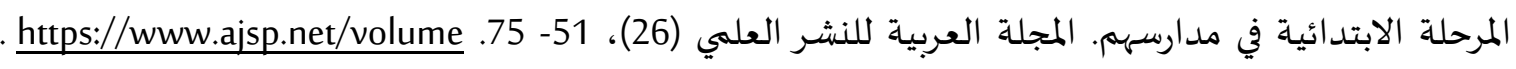
.php?vol=6\# 
- الشثري، وداد بنت عبد الله بن عبد العزيز؛ العبيكان، ريم بنت عبد المحسن بن محمد. (2016). أثر التدريس

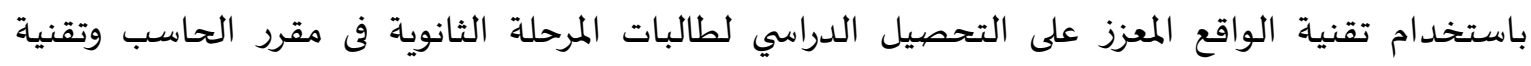
المعلومات. العلوم التربوية 4 (4)، 137 - 173.

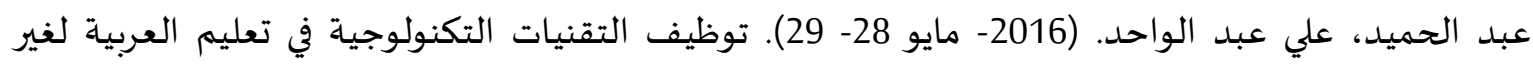

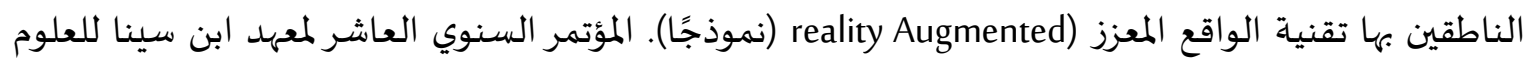
الإنسانية. باريس. عبد الرازق، فاطمة زكريا محمد. (2019). سيناريوهات بديلة لتطوير سياسات الجامعات الحكومية المصرية في

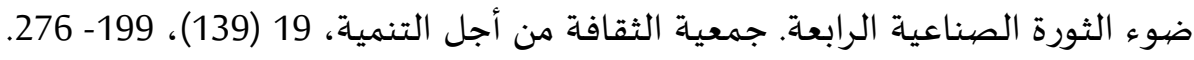

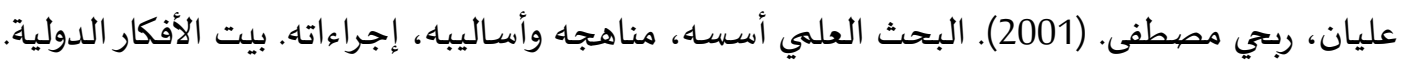

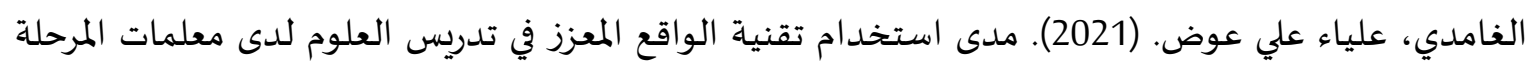
الابتدائية بمحافظة المخواة. (رسالة ماجستير، غير منشورة). جامعاة بيشة.

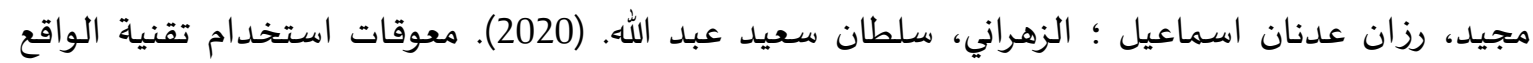

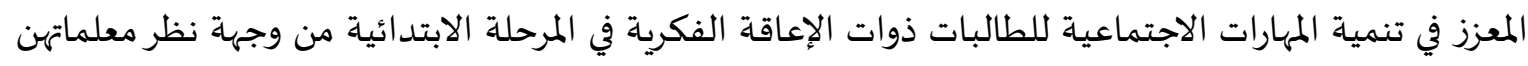

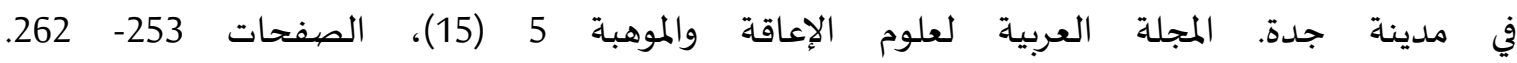
./issue_20321_20322_htmlhttps://jasht.journals.ekb.eg محمد، فاطمة علي صادق. (2019). أثر استخدام تقنية الواقع المعزز (Reality Augmented) في تدريس العلوم على مستوى التحصيل لدى تالميذ الصف الخامس الابتدائي. (رسالة ماجستير، جامعة الكويت). .http://hdl.handle.net/123456789/1073 مشتهي، رامي رياض. (2015). فاعلية توظيف تقنية الحقيقة المدمجة في تنمية مهارات التفكير الإبداعي والاتجاه

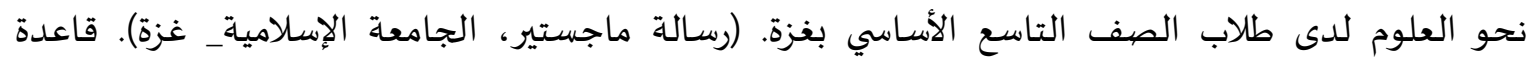
معلومات شمعة للبحوث.

المؤتمر الدولي. (2019، يناير 21- 23). الثورة الصناعية الرابعة وأثرها على التعليم، وزارة التربية والتعليم

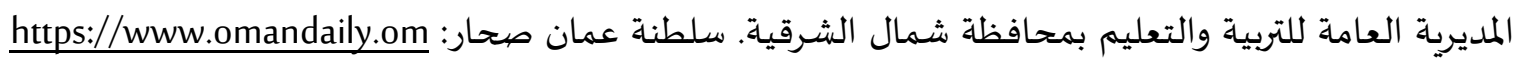
$. / p=665690$

وزارة التربية والتعليم (2020). احصائيات عدد المعلمين والمعلمات 2020. دائرة التخطيط. بجنوب الشرقية. وطفة، علي أسعد. (30 يونيو، 2019). الثورة الصناعية تحديات أم فرص؟ تم الماتئ الاسترداد من مؤسسة النور

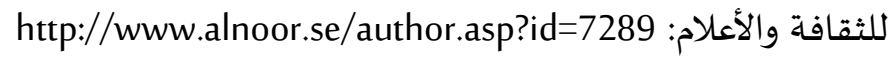

ثانياً- المراجع بالإنجليزية:

- Azuma, R. (1999). The challenge of making augmented reality work outdoors. Mixed reality: Merging real and virtual worlds.(ed.), Springer-Verlag.

- Azuma, R., Baillot, Y., Behringer, R., Feiner, S., Julier, S., \& Maclntyre, B. (2001). Recent advances in augmented reality. IEEE computer graphics and applications, 21(6), 34-47.

- Borlido, D. (2017). Indústria 4.0 - Aplicação a Sistemas de Manutenção. (Dissertação de Mestrado, Universidade do Porto). https://repositorio aberto.up.pt/bitstream/10216/102740/2/181981.pdf. 
- Dunleavy, M., \& Dede, C. (2014). Augmented Reality Teaching and Learning. In J. Michael Spector, M. David Merrill, J. Elen, \& M. J. Bishop (Eds.), Handbook of Research on Educational Communications and Technology (pp. 735-745). New York: Springer.

- Koçak, O., YILMAZ, R., Küçük, S., \& Göktaş, Y. (2019). The educational potential of augmented reality technology: Experiences of instructional designers and practitioners. Journal of Education and Future, (15), 17-36.

- Laudante, E. (2017). Innovation and Design. A new approach for ergonomic analysis in manufacturing system. The Design Journal, 20(1),2724-2734.

- Osuna, J., Gutiérrez-Castillo, J., Llorente-Cejudo, M., \& Ortiz, R. (2019). Difficulties in the incorporation of augmented reality in university education: Visions from the experts. Journal of New Approaches in Educational Research (NAER Journal), 8(2), 126-141. doi.org/10.7821/naer.2019.7.409.

- Poetker, B. (2019, August 22). A Brief History of Augmented Reality (+Future Trends \& Impact). Retrieved from Learning Hub: https://learn.g2.com/history-of-augmented-reality

- Putiorn, P., Nobnop, P., Buathong, P., \& Soponronnarit, K. (25-28 Nov. 2018). https://www.researchgate.net/publication/332374721_Understanding_Teachers'_Perception_Towar d_the_Use_of_an_Augmented_Reality-

Based_Application_for_Astronomy_Learning_in_Secondary_Schools_in_Northern_Thailand. 2018 Global Wireless Summit (GWS). Chiang Rai, Thailand: (GWS) (pp. 77-81). IEEE.

- Schwab, K. (2016). The Fourth Industrial Revolution. file:///C:/Users/moe/Desktop/ 1BB7A 1/4EB1 1/0ACC 1/DA39 1/62F3 1/1694 1/D9C8 1.PDF.

- Sharma, A., \& Jain, D. (2020). Development of Industry 4.0. In A Roadmap to Industry 4.0: Smart Production, Sharp Business and Sustainable Development, 23- 38, https://doi.org/10.1007/978-3030-14544-6_2.

- Stăncioiu, A. (2017). THE FOURTH INDUSTRIAL REVOLUTION „INDUSTRY 4.0". Fiabilitate Şi Durabilitate, (1), 74-78. https://www.semanticscholar.org/paper/THE-FOURTH-INDUSTRIALREVOLUTION-\%E2\%80\%9EINDUSTRY-4.0\%E2\%80\%9DSt\%C4\%83ncioiu/66762e6431110b462a45091878daec6e51901dae.

- Waschkus, E. (2018). Systematische Analyse des aktuellen Forschungsstandes von Prozessmodellen im Kontext der Industrie 4.0. (Doctoral dissertation, Ulm University).

- Yuen, S., Yaoyuneyong, G., \& Johnson, E. (2011). Augmented reality: An overview and five directions for AR in education. Journal of Educational Technology Development and Exchange (JETDE), 4(1), $119-140$. 